\title{
Experimental and Numerical Investigation of Flow Measurement Mechanism and Hydraulic Performance of Portable Pillar-Shaped Flumes in Rectangular Channels
}

\author{
Bin Sun, Lei Yang, Shun Zhu, Quan Liu, Chao Zhang ${ }^{D}$, and Jinping Zhang \\ School of Water Conservancy Engineering, Zhengzhou University, Zhengzhou 450001, China \\ Correspondence should be addressed to Chao Zhang; chao.zhang.zzu@outlook.com
}

Received 30 June 2020; Revised 13 July 2020; Accepted 18 July 2020; Published 8 August 2020

Academic Editor: Hong-jun Zhu

Copyright ( 2020 Bin Sun et al. This is an open access article distributed under the Creative Commons Attribution License, which permits unrestricted use, distribution, and reproduction in any medium, provided the original work is properly cited.

\begin{abstract}
Based on the principle of the critical flow and standard $\mathrm{k}-\varepsilon$ three-dimensional turbulence model, experiments and simulations were performed on a portable pillar-shaped flume with three contraction ratios under 12 working conditions. By combining the numerical simulations with the experiments, the theoretical stage-discharge formula of the portable pillar-shaped flume was developed, and the variations in the Froude number, backwater height, critical submergence, head loss, and velocity distribution were examined. The simulation data obtained from the standard $k-\varepsilon$ three-dimensional turbulence model are in good agreement with the experimental results, with a maximum error of $8.65 \%$. The maximum error in the difference between the theoretical stagedischarge formula and the measured value is $4.74 \%$. The upstream Froude number is less than 0.5, and critical submergence is between 0.73 and 0.96 . Compared to airfoil pillar-shaped flumes, the portable pillar-shaped flume had a significantly smaller head loss and backwater height. Finally, the portable pillar-shaped flume can be used for flow measurement and has the advantages of high measurement accuracy, low backwater height, and small head loss.
\end{abstract}

\section{Introduction}

Rectangular channels, as an indispensable infrastructure in economic development, deal with the transportation of water resources, irrigation, water pollution control, flood prevention, storm drainage, and other important functions. It is widely used in the construction of water conservancy, especially in areas where the cultivated land resources are scarce or the efficiency of the cultivated land resources is high. Flow measurement is an important basis for optimizing the allocation of water resources and monitoring water quantity [1-3].

At present, although there are various methods for measuring the flow of open channels, flow measurement based on the concept of critical flow is the most widely used technique, and flumes with a local contraction of channel are universally applied as discharge measurement structures, especially in scientific and hydrological research in irrigation systems [4-6]. Based on the principle of Venturi flume [7],
Parshall proposed a representative Parshall flume [8]. Skogerboe et al. [9-11] conducted experimental research on flow measurement under free and submerged conditions of a Parshall flume. In the field of fluid mechanics, the cylinder is often used to study vibration and energy collection [12-16], and it can also be used in the field of flow measurement. The turbulence characteristics of using the cylinder in the channel to measure the flow are similar to the problem of the flow around the cylinder. For example, unlike a Parshall flume, an improved venturi channel which had a contraction along the channel axis rather than its side walls was proposed by Hager [17], central baffle flume was proposed by Kolavani et al. and Bijankhan and Ferro, and the stage-discharge curve of the central baffle flume was studied experimentally $[18,19]$. Each of the above studies has proposed a new type of measuring flume and analyzed its hydraulic characteristics. However, there are few studies on the optimization of the shape of the measuring flume according to the specific hydraulic characteristics. Sun et al. [20] performed the 
multiobjective optimization of an airfoil-shaped hydraulic structure based on National Advisory Committee for Aeronautics (NACA) thickness distribution and obtained the optimized airfoil profile control equation. They also compared the solutions before and after optimization and showed that the optimized airfoil-shaped flume had a smoother flow and a smaller head loss.

Based on reviewing previous research studies, it can be concluded that reducing the head loss and increasing the overcurrent capacity as much as possible without decreasing the measurement accuracy will be an important aspect of future research. Additionally, most types of the measuring flumes cannot be applied to the channels already constructed and cannot be installed and removed conveniently. Thus, in order to solve these problems, this paper presents a portable pillar-shaped flume based on the optimized airfoil equation [20]. Currently, most research in the field of fluids is based on the combination of numerical simulation and model experiments [21-25]. Numerical simulation has become an important method for examining new water measuring facilities, especially in the study of open channel hydraulics $[1,21,26-29]$. In order to further study the internal flow field distribution and to provide a theoretical basis for the optimization and promotion of the portable pillar-shaped flume, its hydraulic characteristics are analyzed by means of computational fluid dynamics (CFD) using Fluent 19.2 software, which can accurately and conveniently compute and visualize the results.

\section{Materials and Methods}

\subsection{The Experimental Set-Up}

2.1.1. Structure of the Portable Pillar-Shaped Flume. In order to solve the problem of the NACA airfoil-shaped flume, i.e., its proneness to water blocking under low head conditions, the NACA airfoil equation is moderately adjusted and finely optimized by utilizing parametric methods and the theory of optimization algorithm. To this end, a new airfoil equation with better overcurrent characteristics is finally obtained. The airfoil profile of the portable pillar-shaped flume is controlled by this optimized equation [20]:

$$
\begin{aligned}
y= & 10 P\left[0.2737 \sqrt{\frac{x}{C}}-0.4263 \frac{x}{C}+1.1660\left(\frac{x}{C}\right)^{2}\right. \\
& \left.-1.7570\left(\frac{x}{C}\right)^{3}+0.7453\left(\frac{x}{C}\right)^{4}\right],
\end{aligned}
$$

where $P$ is the maximum thickness of flume $(\mathrm{m}), C$ represents its length $(\mathrm{m})$, and $x$ and $y$ represent the coordinate of the equation on the $X$-axis and $Y$-axis.

The curve of optimized NACA airfoil equation is shown in Figure 1(a); the shapes of the NACA airfoil-shaped flume and portable pillar-shaped flume are shown in Figure 1(b). Plan-view and profile-view sketches of the portable pillarshaped flume are also illustrated in Figure 2. In this paper, three portable pillar-shaped flumes with different contraction ratios were studied. Moreover, the parts of the hydraulic characteristics of the airfoil pillar-shaped flume controlled by the NACA airfoil equation were studied in the same way and compared with the portable pillar-shaped flume. The contraction ratio is defined as the ratio of the area of the throat section to the total area of the channel section:

$$
\varepsilon=\frac{A_{c}}{A},
$$

where $\varepsilon$ is contraction ratio, $A_{c}$ is the area of the throat section $\left(\mathrm{m}^{2}\right)$, and $A$ represents the total area of the channel section $\left(\mathrm{m}^{2}\right)$.

2.1.2. Experimental Setup. The portable pillar-shaped flume used herein was installed in the Hydraulic Laboratory of the School of Water Conservancy Engineering of Zhengzhou University, Zhengzhou, China. The experimental system consists of an upstream reservoir, a downstream reservoir, a pump, an electromagnetic flowmeter, a water circulation pipe, a rectangular plexiglass channel, a valve, a portable pillarshaped flume, and a sluice gate. Experiments were performed on a portable pillar-shaped flume with three contraction ratios under 12 working conditions (flow approximately ranging from 5 to $27 \mathrm{~L} / \mathrm{s}$ ) and 36 sets of experimental data were finally obtained. An electromagnetic flowmeter is installed in the water circulation pipe section to facilitate monitoring of the flow. The water level stylus is used to measure the water level of the channel flow with a measurement accuracy of $0.1 \mathrm{~mm}$. The comprehensive roughness of the channel is 0.011 . The total length of the rectangular channel is $12 \mathrm{~m}$, and the width of the channel is $0.3 \mathrm{~m}$. A sketch of the experimental setup of the portable pillar-shaped flume is depicted in Figure 3.

The model experiments on the hydraulic performance of the portable pillar-shaped flume were conducted using this channel with three different contraction ratios. The detailed characteristics of the portable pillar-shaped flumes are listed in Table 1. Locations of the typical cross section of the flume for water depth at the centerline of the channel are listed in Table 2.

\subsection{Deriving the Theoretical Discharge Calculation Formula.} The theoretical discharge calculation formula of the portable pillar-shaped flume can be derived by the critical flow equation and the dimensional analysis method. According to the $\Pi$ theorem of dimensional analysis, after analyzing the hydraulic elements of the experimental process and the phenomenon of flow, the physical quantities affecting the flow process of the portable pillar-shaped flume are determined. The hydraulic characteristics of the portable pillarshaped flume under free-flow conditions (Figure 2) can be expressed by the following functional relationship:

$$
F\left(B_{c}, g, \rho, K_{c}, H\right)=0
$$

where $F$ is a functional symbol, $B_{c}$ is the throat width $(\mathrm{m}), g$ represents acceleration due to gravity $\left(\mathrm{m} / \mathrm{s}^{2}\right), \rho$ indicates the density of fluid $\left(\mathrm{kg} / \mathrm{m}^{3}\right), K_{c}$ is the critical water depth $(\mathrm{m})$, and $H$ stands for the depth of the upstream water $(m)$.

There are five physical quantities in the above formula, and $B_{c}, g$, and $\rho$ are selected as the basic physical quantities. The above equation can be described by two dimensionless numbers: 


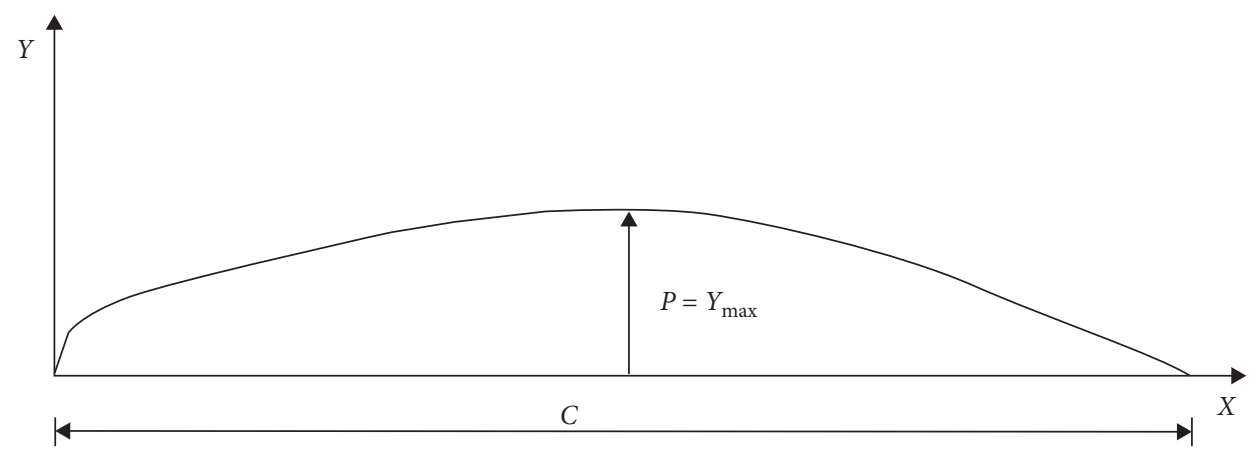

(a)

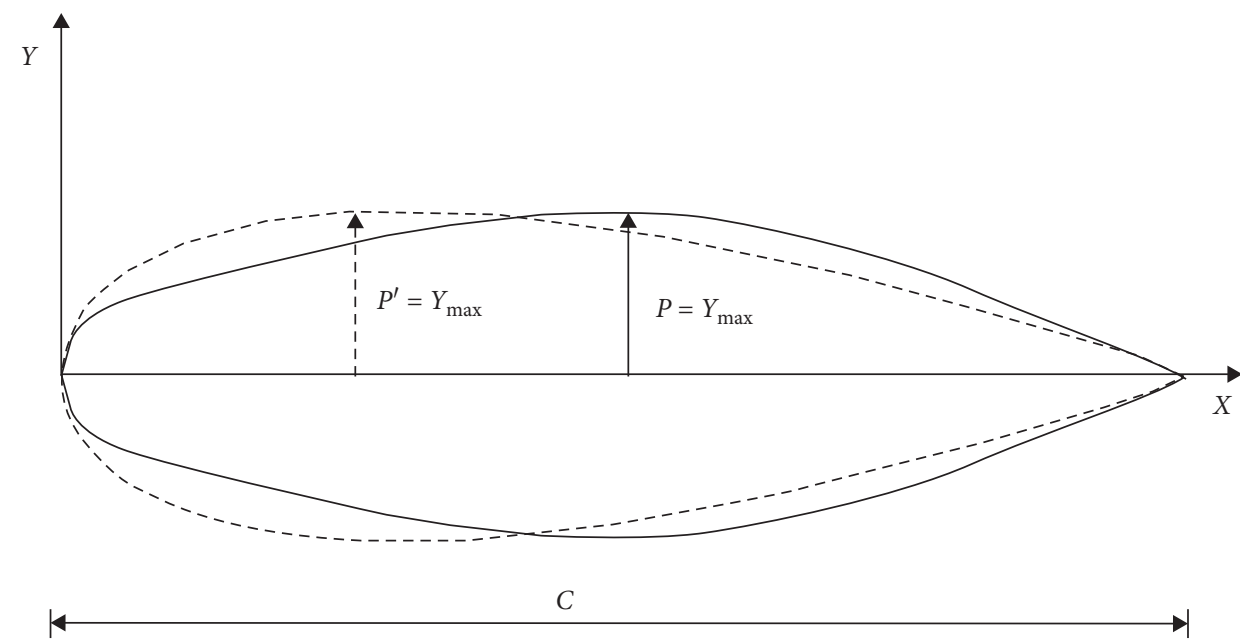

- - NACA airfoil pillar-shaped flume

— Portable pillar-shaped flume

(b)

FIGURE 1: (a) The curve of optimized NACA airfoil equation; (b) the shapes of the NACA airfoil-shaped flume and portable pillar-shaped flume.

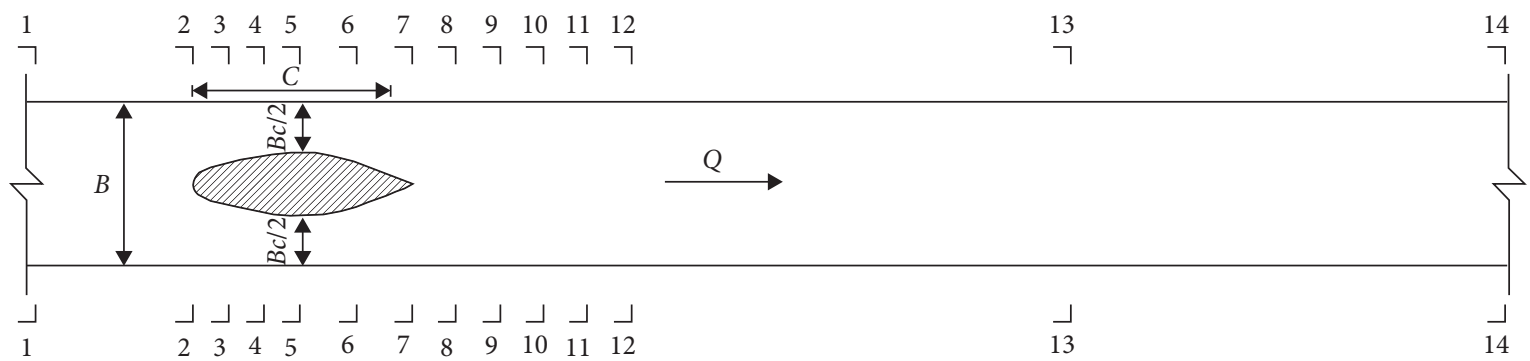

(a)

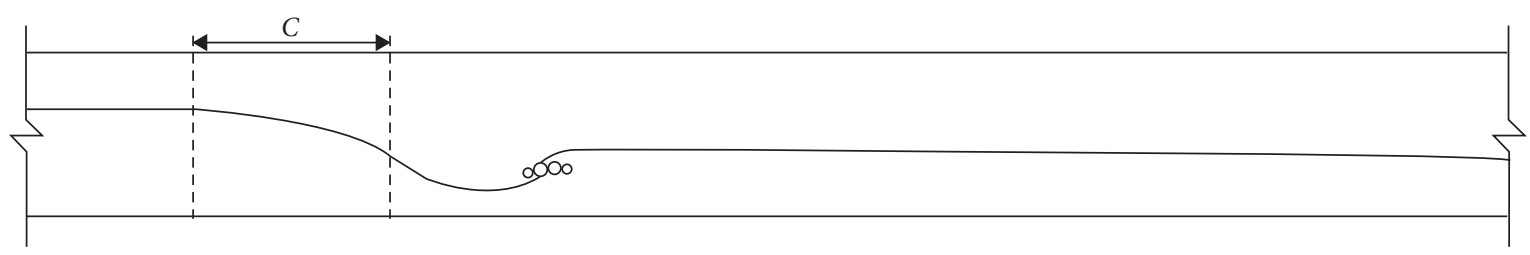

(b)

Figure 2: The (a) plan-view and (b) profile-view of a portable pillar-shaped flume. 


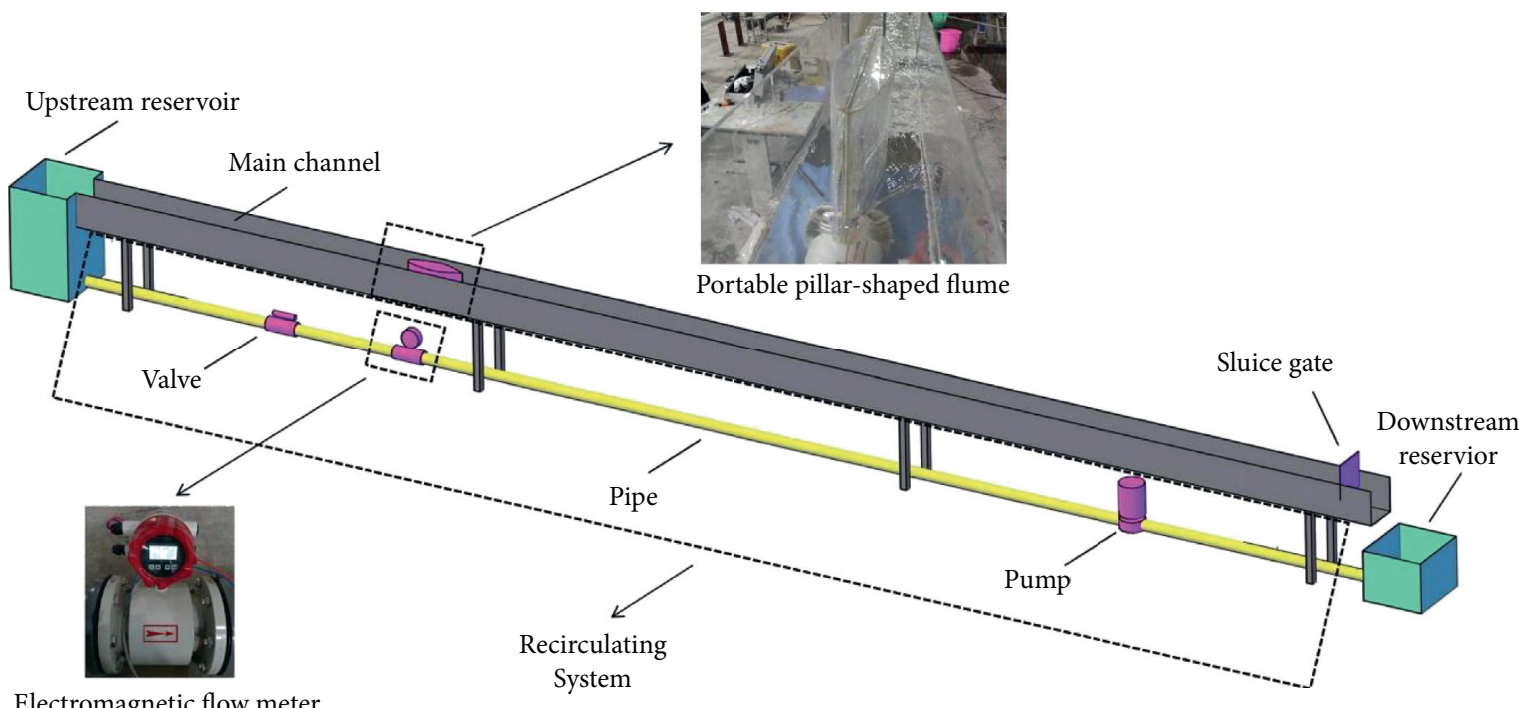

Figure 3: A sketch of the experimental setup.

TABle 1: Dimensions of the portable pillar-shaped flumes with different contraction ratios.

\begin{tabular}{lllll}
\hline Channel width $(\mathrm{cm})$ & $P(\mathrm{~cm})$ & $C(\mathrm{~cm})$ & $B_{c}(\mathrm{~cm})$ & $\varepsilon$ \\
\hline 30 & 9.0 & 50 & 12 & 0.4 \\
30 & 7.5 & 50 & 15 & 0.5 \\
30 & 6.0 & 50 & 18 & 0.6 \\
\hline
\end{tabular}

TABle 2: Locations of the typical cross-section of the flume for water depth at the centerline of the channel.

\begin{tabular}{lc}
\hline Section & Distance from the inlet to the measuring points $(\mathrm{m})$ \\
\hline 1 & 2.500 \\
2 & 3.000 \\
3 & 3.100 \\
4 & 3.200 \\
5 & 3.245 \\
6 & 3.400 \\
7 & 3.500 \\
8 & 3.600 \\
9 & 3.700 \\
10 & 3.800 \\
11 & 3.900 \\
12 & 4.000 \\
13 & 5.000 \\
14 & 6.000 \\
\hline
\end{tabular}

$$
F\left(\Pi_{1}, \Pi_{2}\right)=0 \text {, }
$$

where $\Pi_{1}$ and $\Pi_{2}$ are the dimensionless numbers expressed by

$$
\begin{aligned}
& \Pi_{1}=\frac{H}{B_{c}^{x_{1}} g^{y_{1}} \rho^{z_{1}}}, \\
& \Pi_{2}=\frac{K_{C}}{B_{c}^{x_{2}} g^{y_{2}} \rho^{z_{2}}},
\end{aligned}
$$

where $x_{1}, y_{1} z_{1}, x_{2}, y_{2}$, and $z_{2}$ are determined according to the principle of dimensional harmony:

$$
\begin{aligned}
& {[H]=\left[B_{c}\right]^{x_{1}}[g]^{y_{1}}[\rho]^{z_{1}},} \\
& {\left[K_{c}\right]=\left[B_{c}\right]^{x_{2}}[g]^{y_{2}}[\rho]^{z_{2}} .}
\end{aligned}
$$

Length $(L)$, time $(T)$, and mass $(M)$ are the basic dimensions, so equations (7) and (8) can be rewritten as follows:

$$
\begin{aligned}
& {[L]=[L]^{x_{1}}\left[L T^{-2}\right]^{y_{1}}\left[M L^{-3}\right]^{z_{1}},} \\
& {[L]=[L]^{x_{2}}\left[L T^{-2}\right]^{y_{2}}\left[M L^{-3}\right]^{z_{2}} .}
\end{aligned}
$$

Since the exponents of the same dimension on both sides of the equation are equal, $x_{1}, y_{1}, z_{1}, x_{2}, y_{2}$, and $z_{2}$ can be solved as follows: $x_{1}=1, y_{1}=0, z_{1}=0, x_{2}=1, y_{2}=0$, and $\mathrm{z}_{2}=0$. Thus, equations (5) and (6) can be changed to

$$
\begin{gathered}
\Pi_{1}=\frac{K_{c}}{B_{c}}, \\
\Pi_{2}=\frac{H}{B_{c}} .
\end{gathered}
$$

By substituting equations (11) and (12) into equation (4), the dimensionless number equation can be obtained:

$$
F\left(\frac{K_{c}}{B_{c}}, \frac{H}{B_{c}}\right)=0,
$$

so

$$
\frac{K_{c}}{B_{c}}=\varphi\left(\frac{H}{B_{c}}\right),
$$

where $\varphi$ is a functional symbol.

Transforming equation (14) into an explicit form leads to

$$
\frac{K_{c}}{B_{c}}=a\left(\frac{H}{B_{c}}\right)^{n},
$$

where $n$ is an undetermined number that can be obtained by experimental data and $a$ indicates a constant value divided by the contraction ratio of the portable pillar-shaped flume. 
A critical flow is created in the portable pillar-shaped flume by installing an airfoil pillar across the flow. If we suppose that a critical flow is formed at the throat of the flume, from the critical flow equation, one may obtain

$$
\begin{gathered}
Q=\left(\frac{g A_{c}^{3}}{B_{c}}\right)^{(1 / 3)}, \\
A_{c}=B_{c} K_{c},
\end{gathered}
$$

where $Q$ is the discharge rate $(\mathrm{L} / \mathrm{s})$.

$K_{c}$ can also be obtained from equations (16) and (17):

$$
K_{c}=\frac{Q^{(2 / 3)}}{g^{(1 / 3)} B_{c}^{(2 / 3)}}
$$

Equation (18) is substituted into equation (15) as follows:

$$
\frac{Q^{(2 / 3)}}{g^{(1 / 3)} B_{c}^{(5 / 3)}}=a\left(\frac{H}{B_{c}}\right)^{n} \text {. }
$$

The above equation can also be written as the explicit function of flow as follows:

$$
Q=a^{(2 / 3)} g^{(1 / 2)} B_{c}^{2.5-1.5 n} H^{1.5 n}
$$

\subsection{Numerical Simulation}

2.3.1. Governing Equations and Turbulence Model. In this study, Fluent 19.2 was utilized to solve the computational fluid dynamics simulations. The volume-of-fluid (VOF) method [30-33] and the standard $k-\varepsilon$ three-dimensional turbulence model [32] were chosen to simulate the flow domain in the portable pillar-shaped flume. The motion of Newtonian fluid flowing through the portable pillar-shaped flume is described by the continuity and Navier-Stokes equations, i.e., respectively, equations (21) and 22(a-c):

$\frac{\partial \rho}{\partial t}+\frac{\partial(\rho u)}{\partial x}+\frac{\partial(\rho v)}{\partial y}+\frac{\partial(\rho w)}{\partial z}=0$

$$
\begin{gathered}
\frac{\partial(\rho u)}{\partial t}+\operatorname{div}(\rho u \mathbf{u})=-\frac{\partial p}{\partial x}+\operatorname{div}(\mu \operatorname{grad} u)+F_{x}, \\
\frac{\partial(\rho v)}{\partial t}+\operatorname{div}(\rho v \mathbf{u})=-\frac{\partial p}{\partial y}+\operatorname{div}(\mu \operatorname{grad} v)+F_{y}, \\
\frac{\partial(\rho w)}{\partial t}+\operatorname{div}(\rho w \mathbf{u})=-\frac{\partial p}{\partial z}+\operatorname{div}(\mu \operatorname{grad} w)+F_{z},
\end{gathered}
$$

where the concepts of divergence and gradient are introduced as $\operatorname{div}(a)=\left(\partial a_{x} / \partial x\right)+\left(\partial a_{y} / \partial y\right)+\left(\partial a_{z} / \partial z\right)$ and $\operatorname{grad}(b)=(\partial b / \partial x)+(\partial b / \partial y)+(\partial b / \partial z), u, v$, and $w$ represent average flow velocity components in Cartesian coordinates $x, y$, and $z$, respectively $(\mathrm{m} / \mathrm{s}), F_{x}, F_{y}$, and $F_{z}$ stand for body forces $(\mathrm{N}), p$ is pressure (pa) $t$ is time (s), and $\rho$ represents the density of fluid $\left(\mathrm{kg} / \mathrm{m}^{3}\right)$.
The standard $\mathrm{k}-\varepsilon$ models include turbulent energy equation and turbulent dissipation equation. The equations for the turbulent kinetic energy and the dissipation rate of the standard $\mathrm{k}-\varepsilon$ model are defined as follows:

$$
\begin{aligned}
& \rho \frac{d k}{d t}=\frac{\partial}{\partial x_{i}}\left[\left(\mu+\frac{\mu_{t}}{\sigma_{k}}\right) \frac{\partial_{k}}{\partial x_{i}}\right]+G_{k}+G_{b}-\rho \alpha, \\
& \rho \frac{\mathrm{d} \varepsilon}{\mathrm{d} t}=\left[\left(\mu+\frac{\mu_{t}}{\sigma_{\varepsilon}}\right) \frac{\partial \varepsilon}{\partial x_{i}}\right]+C_{1 \varepsilon} \frac{\varepsilon}{k}\left(G_{k}+C_{3 \varepsilon} G_{b}\right)-C_{2 \varepsilon} \rho \frac{\varepsilon^{2}}{k},
\end{aligned}
$$

where $k$ is the turbulent kinetic energy $\left(\mathrm{m}^{2} / \mathrm{s}^{2}\right), \alpha$ is turbulent energy dissipation rate $\left(\mathrm{kg} \cdot \mathrm{m}^{2} / \mathrm{s}^{3}\right), G_{k}$ is turbulent energy caused by average velocity gradient, $G_{b}$ is turbulent energy caused by buoyancy, and $\mu_{t}$ is fluid turbulent viscosity (N.s/ $\mathrm{m}^{2}$ ). In this paper, $\sigma_{k}=1.39, \sigma_{\alpha}=1.39, C_{1 \varepsilon}=1.42, C_{2 \varepsilon}=1.68$, and $C_{3 \varepsilon}=0.09$.

2.3.2. Model Establishment. ANSYS DesignModeler is employed to create the portable pillar-shaped flume geometry models with three different contraction ratios. In order to make the flow pattern of the simulated channel as similar as possible to the actual experimental results, simulate according to the geometry of the model experiments. The bottom center point of the upstream section of the flume is selected as the coordinate origin, the positive direction of the $X$-axis is the direction of the water flow, the positive direction of the $Y$-axis is the direction of the left bank of the channel, and the negative direction of the $Z$-axis is the direction of gravity acceleration.

\subsubsection{Mesh Generation and Boundary Conditions.} ANSYS meshing is utilized to establish meshes for the flow domain. The model uses hexahedron structured grids with a unit size of $0.02 \mathrm{~m}$. Due to the drastic changes in the water flow conditions near the portable pillar-shaped flume, a local grid encryption process is employed to simulate the water flow conditions near the flume more accurately and the grid unit size is set at $0.01 \mathrm{~m}$.

The boundary conditions of the model are set according to the actual conditions of the experiment. The inlet is divided into a lower water inlet (inlet 1 ) and an upper air inlet (inlet 2). The type of the water inlet is set at velocity inlet, and the air inlet is set at pressure inlet; the outlet is set at pressure outlet (pressure-outlet), and the wall boundary (wall) selected has no slip option. According to the actual situation of the model experiment, the roughness (roughness height) is set at $0.000011 \mathrm{~m}$. The boundary conditions of the flume model are displayed in Figure 4.

\section{Results and Discussion}

3.1. Verification of the Numerical Simulation. Many researchers have verified that Fluent software can be utilized for the simulation of flow measuring flumes [34]. In order to further validate the reliability of the simulation, the numerical data are compared with the experimental results of 


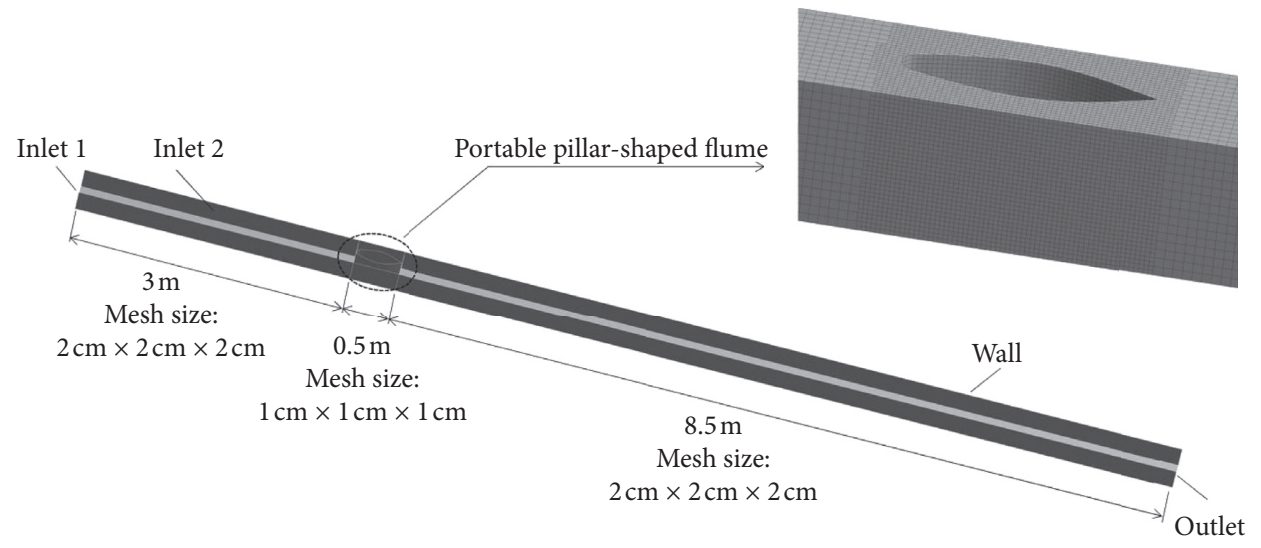

FIgURE 4: Model and boundary conditions of the portable pillar-shaped flume.

water flow patterns and water depths along the water path. According to Figure 5, by comparing the measured and simulated flow patterns, the simulation data are almost consistent with the experimental results of the water flow pattern.

The simulated and experimental results of the free water surface line are also compared in Figure 6. It is obvious that the flow in the upstream section of the portable pillar-shaped flume is relatively smooth, and the flow direction is relatively parallel. After entering the contraction section, the water surface slowly falls, and it drops sharply near the downstream section of the throat. At the same time, the water surface fluctuates strongly. The results demonstrate that the simulation data are consistent with the experimental results with a maximum and average error of 8.65 and $3.45 \%$, respectively. Therefore, we can conclude that Fluent software can reflect the hydraulic characteristics of the flume accurately.

3.2. Discharge Calculation Formula and Its Accuracy. Equation (24) is used to calculate the flow rate of the portable pillar-shaped flume. To determine constants $a$ and $n$ in the equation, one may take the logarithm of both sides of equation (24) to derive

$$
\operatorname{Ln}\left(\frac{K_{c}}{B_{c}}\right)=\operatorname{Ln}(a)+n \operatorname{Ln}\left(\frac{H}{B_{c}}\right) .
$$

The 36 sets of experimental data, i.e., $K_{c} / B_{c}$ and $H / B_{c}$, measured in the portable pillar-shaped flumes with three contraction ratios are plotted on double logarithmic coordinates, as shown in Figure 7. All the test data show a very good correlation regardless of the contraction ratio. Our result is similar to those of Samani, Magallanez, Baiamonte, Ferro (SMBF) flume [35], and triangular central baffle flume [19].

Plotting of the experimental pairs of $\operatorname{Ln}\left(K_{c} / B_{c}\right)$ and $\operatorname{Ln}\left(H / B_{c}\right)$ in Figure 7 revealed that the stage-discharge curves corresponding to different values lie on a single curve. Equation (25) is fitted to the experimental data by using an $a$ and $n$ value of 0.7151 and 1.0377 , respectively, and the square of the correlation coefficient $\left(R^{2}\right)$ is equal to 0.99895 .
Consequently, the following stage-discharge relationship is calibrated using all the available experimental data:

$$
Q=1.8939 B_{c}^{0.9943} H^{1.5566} \text {. }
$$

In order to check the measuring accuracy of the flume, the measured upstream water depth is substituted into equation (26), and the calculated data $\left(Q_{1}\right)$ are compared with the measured results $\left(Q_{2}\right)$ of the electromagnetic flowmeter, as presented in Table 3. The maximum relative error in the flow measurement of the portable pillar-shaped flume is $4.74 \%$, and the relative error in the average current measurement is $1.72 \%$, which proves that the measurement accuracy of the portable pillar-shaped flume examined herein can meet the actual requirements of water measurement, and its flow calculation formula is simple, accurate, and convenient.

3.3. The Froude Number and Submergence Limits. The Froude number is of great significance in analyzing the hydraulic characteristics of the flow of open channels. It is a criterion for judging the flow pattern of open channels and can be used as an important indicator of the water measurement performance of a flume. Its calculation formula is expressed in

$$
F r=\frac{v}{\sqrt{g \bar{h}}}
$$

where $v$ is the average velocity of the channel section $(\mathrm{m} / \mathrm{s}), g$ represents the acceleration of gravity $\left(\mathrm{m} / \mathrm{s}^{2}\right)$, and $\bar{h}$ stands for the average water depth of the section $(\mathrm{m})$.

Herein, various Froude numbers are figured out using the experiments based on three different contraction ratios and 12 discharge rates. Figure 8 illustrates the distribution of the Froude number in the portable pillar-shaped flume along the path when the contraction ratio is 0.5 and the flow rate is $15 \mathrm{~L} / \mathrm{s}$. From an energy point of view, the Froude number represents two times the square of the ratio of the average kinetic energy to the average potential energy per unit mass of liquid in the cross-section. From the entrance of the flume to the front of the diffusion section of the flume, the water surface shows a downward trend, the average potential 


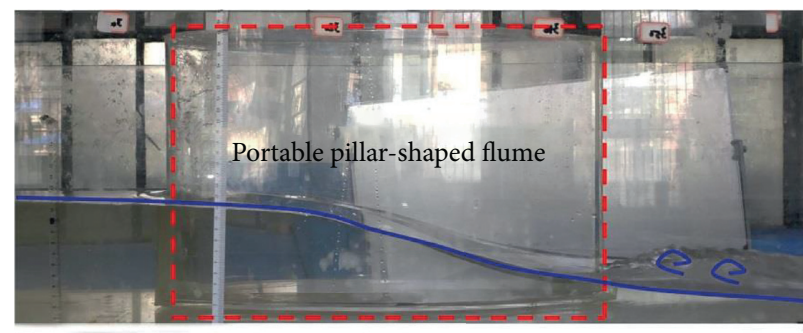

Flow direction

(a)

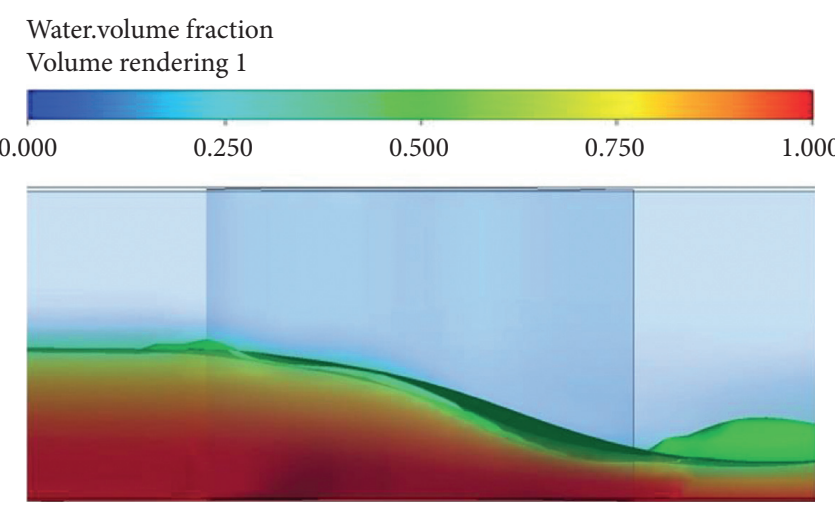

(b)

Figure 5: Comparison of the simulated and experimental flow patterns: (a) profile of the measured flow pattern; (b) profile of the simulated flow pattern.

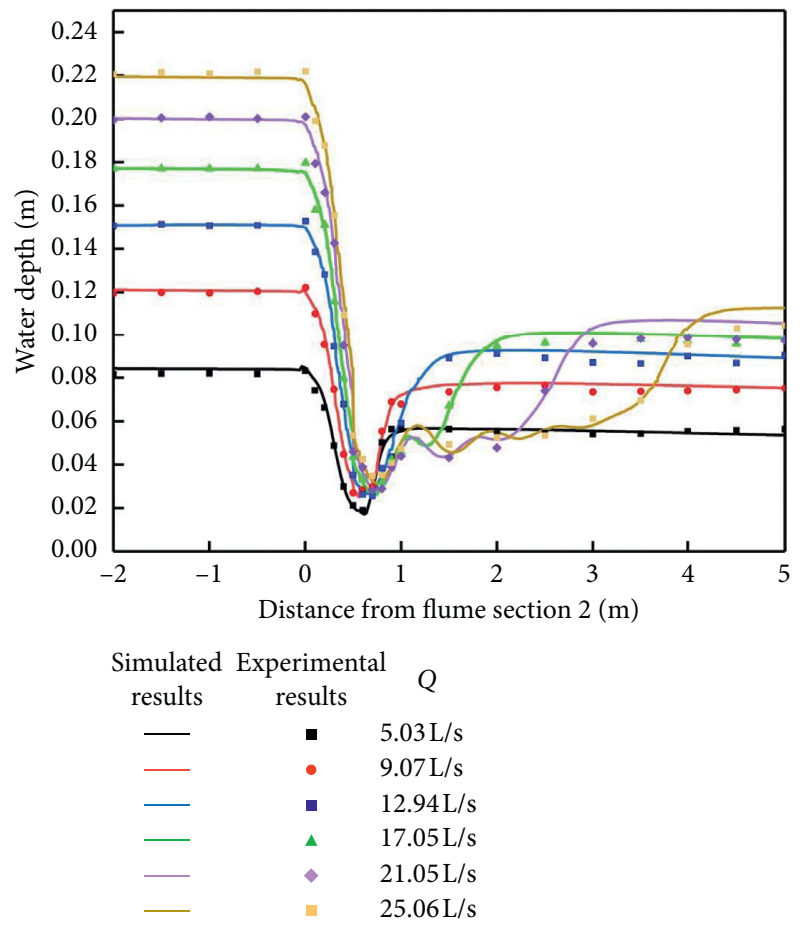

FIGURE 6: Comparison of the simulated and experimental results of free water surface line.

energy gradually decreases, and the average kinetic energy increases, so the Froude number gradually rises. However, in the second half of the trough exit, the water surface has a rising trend, the average potential energy gradually increases, and the average kinetic energy gradually drops, so the Froude number gradually falls.

The Froude number in front of the flume is one of the important factors affecting the flow measurement accuracy of the water flume. An excessively large Froude number in front of the flume may cause large fluctuations in the water surface in the upstream section of the flume, affect the accuracy of the water depth measurement, and reduce the accuracy of the current measurement. Generally, when the flow is measured in an open channel, the Froude number in

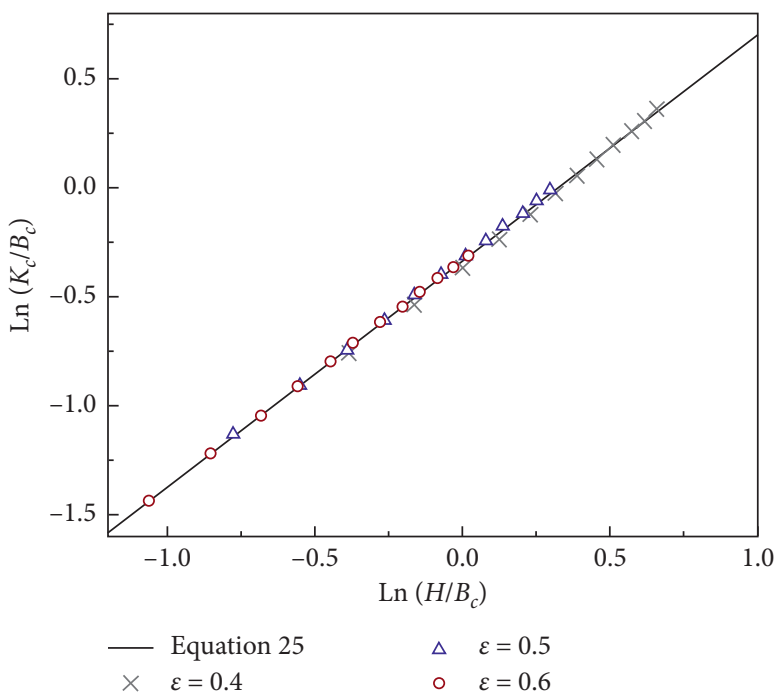

Figure 7: Relationship between $\operatorname{Ln}\left(K_{c} / B_{c}\right)$ and $\operatorname{Ln}\left(H / B_{c}\right)$.

front of the flume is less than 0.5. Froude numbers in Section 1 with different contraction ratios and discharge rates are shown in Figure 9. It can be inferred from Figure 9 that all Froude numbers are less than 0.4 , thereby meeting the requirements for measuring the flow of flume; also, the Froude number is proportional to the contraction ratio. Moreover, at the same contraction ratio, the Froude number rises slightly as the discharge rate increases.

The critical submergence is an important indicator of measuring the performance of a flume and is defined as the ratio of the downstream depth of the flume to the upstream depth of the flume:

$$
S=\frac{h_{d}}{h_{u}}
$$

where $h_{u}$ is the water depth in the upstream section of the flume $(\mathrm{m})$ and $h_{d}$ is the water depth in the downstream section of the flume $(\mathrm{m})$.

By sorting and analyzing the test data, the relationship between the critical submergence of the portable pillarshaped flume and the discharge rate can be figured out, as 
TABLE 3: Comparison of the measured and calculated flow rates at different contraction ratios.

\begin{tabular}{|c|c|c|c|c|}
\hline$\varepsilon$ & $H(\mathrm{~cm})$ & $Q_{1}(\mathrm{~L} / \mathrm{s})$ & $Q_{2}(\mathrm{~L} / \mathrm{s})$ & |Error| (\%) \\
\hline \multirow{12}{*}{0.4} & 8.18 & 5.04 & 5.20 & 3.32 \\
\hline & 10.18 & 7.03 & 7.31 & 4.07 \\
\hline & 12.03 & 9.06 & 9.48 & 4.74 \\
\hline & 13.60 & 11.14 & 11.48 & 3.06 \\
\hline & 15.08 & 12.94 & 13.48 & 4.16 \\
\hline & 16.46 & 15.17 & 15.45 & 1.88 \\
\hline & 17.71 & 17.08 & 17.32 & 1.36 \\
\hline & 18.92 & 18.97 & 19.19 & 1.16 \\
\hline & 20.01 & 21.01 & 20.94 & 0.35 \\
\hline & 21.31 & 23.06 & 23.10 & 0.18 \\
\hline & 22.18 & 25.14 & 24.58 & 2.22 \\
\hline & 23.20 & 27.03 & 26.36 & 2.46 \\
\hline \multirow{12}{*}{0.5} & 6.91 & 5.03 & 4.94 & 1.82 \\
\hline & 8.65 & 7.04 & 7.01 & 0.55 \\
\hline & 10.18 & 9.07 & 9.03 & 0.44 \\
\hline & 11.53 & 11.12 & 10.96 & 1.43 \\
\hline & 12.75 & 12.94 & 12.82 & 1.00 \\
\hline & 13.98 & 15.15 & 14.79 & 2.37 \\
\hline & 15.19 & 17.05 & 16.83 & 1.27 \\
\hline & 16.25 & 18.97 & 18.69 & 1.45 \\
\hline & 17.18 & 21.05 & 20.39 & 3.16 \\
\hline & 18.41 & 23.08 & 22.70 & 1.64 \\
\hline & 19.31 & 25.06 & 24.45 & 2.40 \\
\hline & 20.18 & 27.08 & 26.19 & 3.30 \\
\hline \multirow{12}{*}{0.6} & 6.22 & 5.02 & 4.98 & 0.85 \\
\hline & 7.71 & 7.03 & 6.96 & 0.98 \\
\hline & 9.10 & 9.07 & 9.00 & 0.75 \\
\hline & 10.32 & 11.15 & 10.95 & 1.75 \\
\hline & 11.52 & 13.00 & 13.00 & 0.02 \\
\hline & 12.48 & 15.14 & 14.72 & 2.79 \\
\hline & 13.61 & 17.05 & 16.85 & 1.20 \\
\hline & 14.71 & 19.01 & 19.02 & 0.04 \\
\hline & 15.57 & 21.02 & 20.77 & 1.18 \\
\hline & 16.56 & 23.03 & 22.87 & 0.70 \\
\hline & 17.44 & 25.08 & 24.78 & 1.19 \\
\hline & 18.37 & 27.04 & 26.87 & 0.62 \\
\hline
\end{tabular}

tabulated in Table 4. It is clear that, under the same flow conditions, the critical submergence rises with an increase in the contraction ratio. Moreover, according to Table 4, the maximum critical submergence can reach 0.96 and the average critical submergence is 0.85 . The maximum critical submergence of a cylindrical flow measuring flume is $84 \%$, which indicates that the critical submergence of the portable pillar-shaped flume is high under different flow conditions and at different contraction ratios; thus, it has a large free outflow range.

3.4. Head Loss. The measuring flumes are not allowed to have a large head loss, otherwise they lead to the excessive decantation and silt deformation of the channel. When the flow passes through the portable pillar-shaped flume, the cross-section of the passing water shrinks, changing the overflow of the water from slow to rapid and then to slow, as shown in Figure 10. This results in a large head loss, which is much greater than the head loss along the way. The head loss can be calculated in two ways: one is the difference between the total head losses of the first and last sections of the flume, known as the head loss of the flume; the other is the difference between the total head losses of the upstream section of the flume and the section after the water jump, known as the head loss. This study found that the head loss of the measuring flume is mainly caused by the water jump after the throat section, and it is more meaningful to examine the head loss between the upstream section and the downstream postjump section; therefore, we choose the second method. The total head loss of the section is calculated by

$$
H_{\text {Total }}=z+\frac{\gamma}{p}+\frac{v^{2}}{2 g}
$$

where $H_{\text {Total }}, z, \gamma, p, v$, and $g$ represent total head (m), the height $(\mathrm{m})$ of the free surface from the bottom of the channel, unit weight $\left(\mathrm{N} / \mathrm{m}^{3}\right)$, pressure $(\mathrm{pa})$, velocity $(\mathrm{m} / \mathrm{s})$, and acceleration $\left(\mathrm{m} / \mathrm{s}^{2}\right)$ due to gravity, respectively.

The head loss in this paper is defined as the difference in the head loss of upstream Section 2 and that of downstream Section 12. The head loss is expressed by

$$
h_{w}=H_{u}-H_{d}
$$

where $h_{w}$ is head loss (m), $H_{u}$ is the total head loss of Section $2(\mathrm{~m})$, and $H_{d}$ is total head loss of Section $12(\mathrm{~m})$.

To analyze the head loss of the portable pillar-shaped flume, the development of cross-sectional velocity distributions and turbulent kinetic energy dissipation are simulated for various typical sections.

Turbulent energy dissipation rate refers to the rate at which turbulent flow energy is continuously converted into molecular kinetic energy by internal friction under the action of molecular viscous forces. Studying the turbulent energy dissipation is of great significance to the flow measurement process, and it provides a basis for the evaluation of and improvement in the measuring flume. Figure 11 depicts the development of cross-sectional turbulent kinetic energy dissipation rate in six typical sections (as defined in Figure 2) of the portable pillar-shaped flume when the flow rate is $15 \mathrm{~L} / \mathrm{s}$. Figure 11(a) shows that the flow of the upstream section of the portable pillar-shaped flume is very slow, the speed of water is less than $1 \mathrm{~m} / \mathrm{s}$, the dissipation is concentrated in the area near the wall and bottom, and all the energy dissipation rates are lower than $0.004 \mathrm{~m}^{2} \cdot \mathrm{s}^{-3}$. At the inlet cross-section of the flume, affected by the central column, the water surface is high and the dissipation is concentrated in the middle. The maximum turbulent kinetic energy dissipation rate is $0.02 \mathrm{~m}^{2} \cdot \mathrm{s}^{-3}$, as displayed in Figure 11(b). At the throat (Figure 11(c)), the cross-section of the water decreases, the speed of the water increases, and the dissipation is concentrated in the area near the wall and bottom. The maximum turbulent energy dissipation rate is $0.03 \mathrm{~m}^{2} \cdot \mathrm{s}^{-3}$. Figure 11(d) illustrates the turbulent kinetic energy dissipation in the outlet section of the flume, where the section velocity reaches the maximum, and the turbulent kinetic energy dissipation rate increases to $0.25 \mathrm{~m}^{2} \cdot \mathrm{s}^{-3}$. Figure 11(e) shows the hydraulic jumping phenomenon in the downstream section of the flume. Turbulent kinetic energy dissipation is mainly concentrated on the surface of 


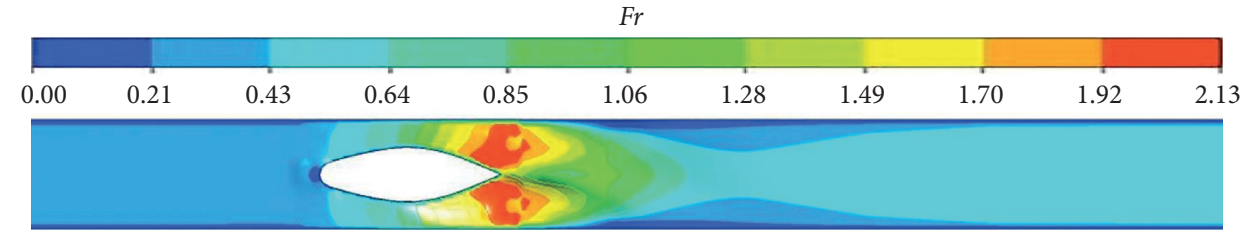

Figure 8: The distribution of the Froude number in the portable pillar-shaped flume.

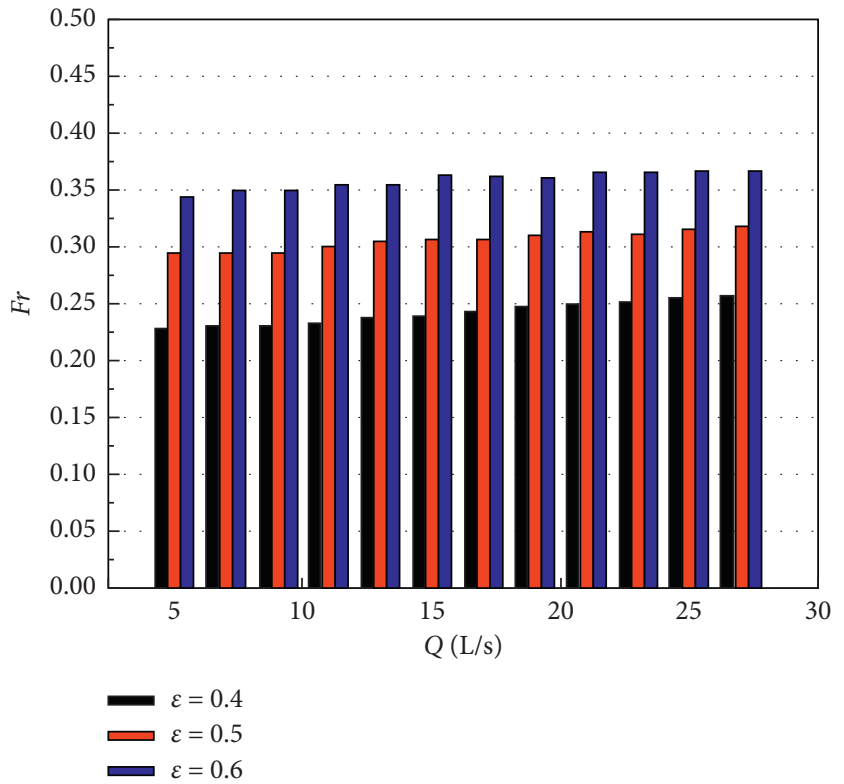

Figure 9: The Froude number at different contraction ratios and discharge rates in Section 1.

TABle 4: Submergence limits at different contraction ratios and discharge rates.

\begin{tabular}{|c|c|c|c|c|c|c|c|c|}
\hline$\varepsilon$ & $Q(\mathrm{~L} / \mathrm{s})$ & $S$ & $\varepsilon$ & $Q(\mathrm{~L} / \mathrm{s})$ & $S$ & $\varepsilon$ & $Q(\mathrm{~L} / \mathrm{s})$ & $S$ \\
\hline \multirow{12}{*}{0.4} & 5.04 & 0.85 & \multirow{12}{*}{0.5} & 5.03 & 0.93 & \multirow{12}{*}{0.6} & 5.02 & 0.96 \\
\hline & 7.03 & 0.88 & & 7.04 & 0.88 & & 7.03 & 0.93 \\
\hline & 9.06 & 0.83 & & 9.07 & 0.92 & & 9.07 & 0.94 \\
\hline & 11.14 & 0.73 & & 11.12 & 0.88 & & 11.15 & 0.86 \\
\hline & 12.94 & 0.77 & & 12.94 & 0.87 & & 13.00 & 0.87 \\
\hline & 15.17 & 0.76 & & 15.15 & 0.86 & & 15.14 & 0.90 \\
\hline & 17.08 & 0.81 & & 17.05 & 0.85 & & 17.05 & 0.90 \\
\hline & 18.97 & 0.82 & & 18.97 & 0.83 & & 19.01 & 0.91 \\
\hline & 21.01 & 0.78 & & 21.05 & 0.86 & & 21.02 & 0.84 \\
\hline & 23.06 & 0.76 & & 23.08 & 0.84 & & 23.03 & 0.86 \\
\hline & 25.14 & 0.81 & & 25.06 & 0.83 & & 25.08 & 0.87 \\
\hline & 27.03 & 0.80 & & 27.08 & 0.80 & & 27.04 & 0.85 \\
\hline
\end{tabular}

the water flow, with a maximum rate of $0.21 \mathrm{~m}^{2} \cdot \mathrm{s}^{-3}$. The flow of the postjump section tends to be stable, and its distribution of the turbulent kinetic energy dissipation is similar to, but higher than, that of the upstream section. Figure 11(f) shows that, due to the hydraulic jump, the total dissipation rate of the turbulent kinetic energy in the diffusion section is quite high, and the dissipation is concentrated in the area near the water surface where the hydraulic jump occurs.

Furthermore, airfoil pillar-shaped flumes [36] with three contraction ratios were tested and simulated in the same way, and the head losses of the portable pillar-shaped flume and airfoil pillar-shaped flume were compared, as presented in Figure 12. It can be seen that the head loss of the portable pillar-shaped flume is significantly lower than that of the airfoil pillar-shaped flume. Similarly, Figure 13 clearly shows that the water head loss of the portable pillar-shaped flume, as a percentage of the total upstream water head loss, is significantly smaller than that of the airfoil pillar-shaped flume.

We also found out that there is a good linear relationship $\left(R^{2}=0.97316\right)$ between the upstream water depth and head loss by sorting the test data (Figure 14). The following equation can be well fitted to the test data:

$$
h_{w}=0.3637 H-0.1282 \varepsilon+0.0539 \text {, }
$$

where $h_{w}$ is head loss $(\mathrm{m}), H$ is the water depth in the upstream section of the flume $(\mathrm{m})$, and $\varepsilon$ is contraction ratio.

Compared with the airfoil pillar-shaped flume, the head loss of the portable pillar-shaped flume is smaller, especially in the case of large contraction ratios.

3.5. Upstream Backwater Height. In the current work, the backwater height is defined as the value added to the original channel water depth after the installation of a flume, and the original channel water depth is measured through the channel under the same flow conditions when the flume is not installed.

The variations in the backwater height of the portable pillar-shaped flume and airfoil pillar-shaped flume versus the discharge rate are delineated in Figure 15. The preliminary analysis of the experimental data shows that the backwater height of the portable pillar-shaped flume is inversely proportional to the contraction ratio and directly proportional to the discharge rate of the flume. Figure 15 clearly indicates that the backwater height of the portable pillar-shaped flume is smaller than that of the airfoil pillarshaped flume, which makes it more suitable for application in the constructed channels.

3.6. Velocity Distribution. Velocity distribution is an important basis for studying the hydraulic characteristics of a flume. Exploiting longitudinal time-averaged velocity distribution for describing the flow of water along the flow direction can reflect the regular pattern of the flow in the portable pillar-shaped flume.

Figure 16 displays the simulated velocity distribution of the longitudinal flow of the water under free flow conditions at a flow rate of $15 \mathrm{~L} / \mathrm{s}$ and a contraction ratio of 0.5 . According to Figure 16(a), because the water flow in the 


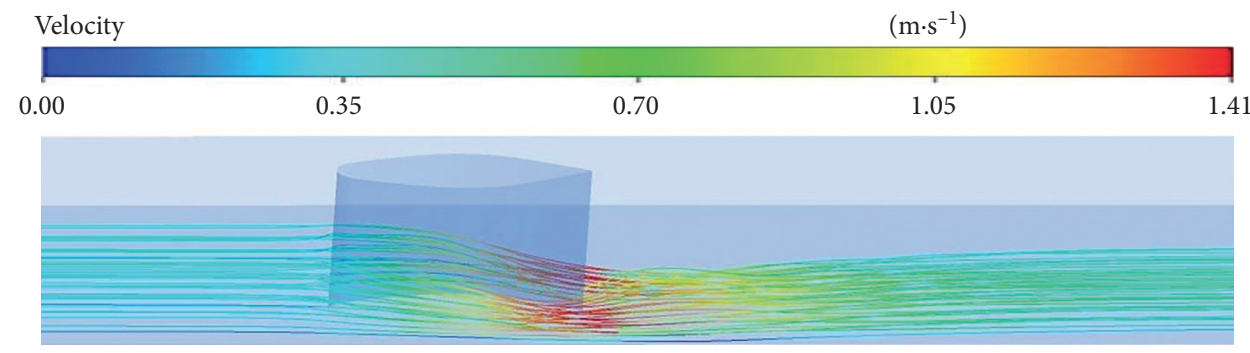

FIgURE 10: The streamline distribution in the portable pillar-shaped flume.

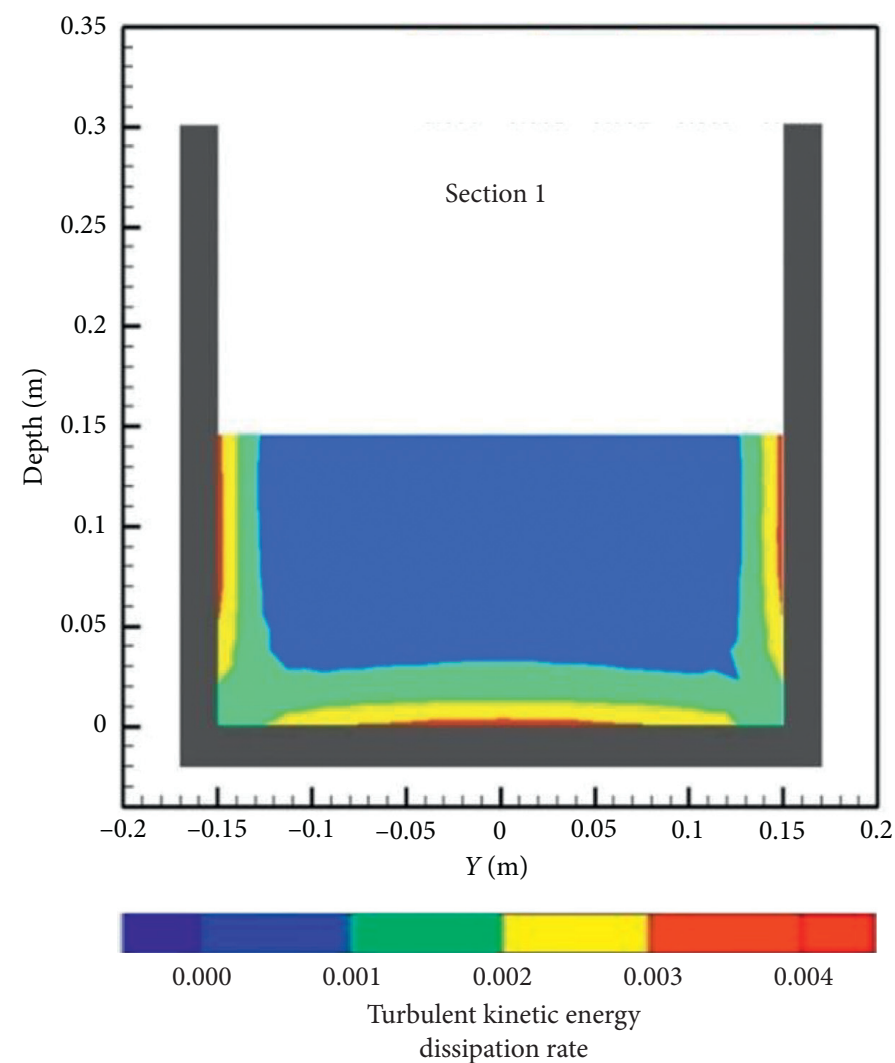

(a)

FIgURE 11: Continued. 


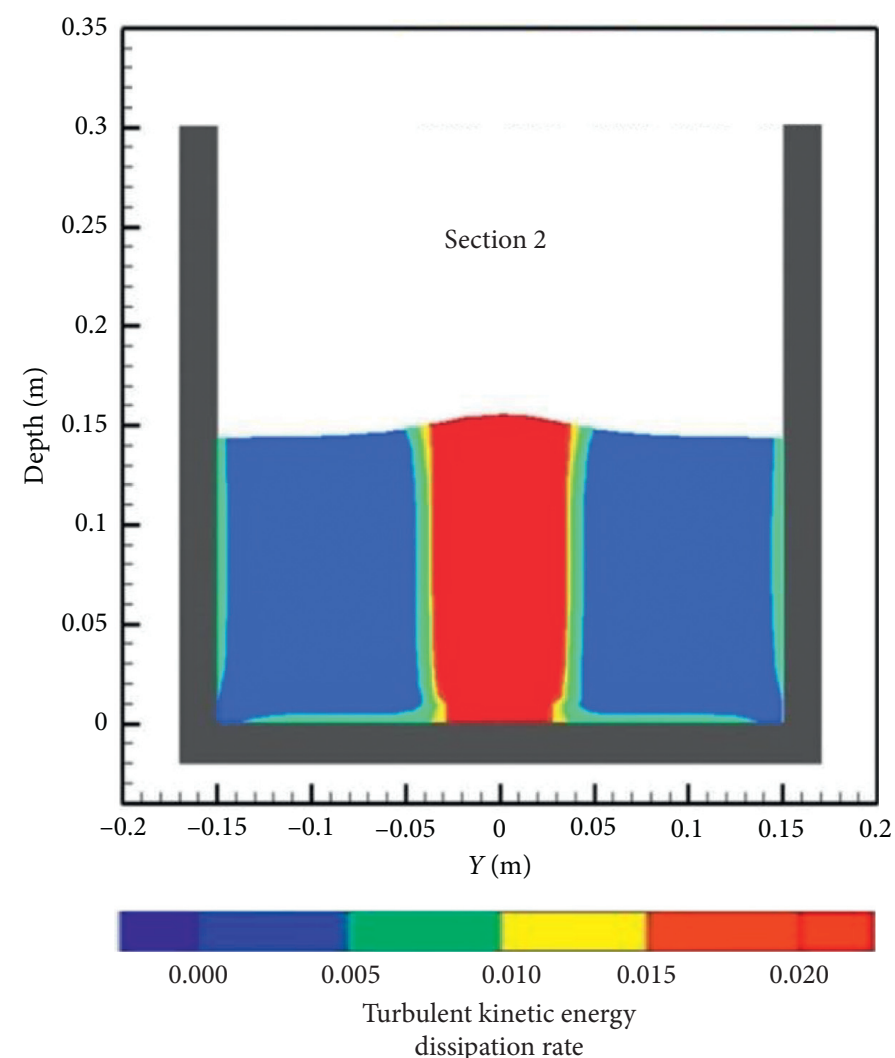

(b)

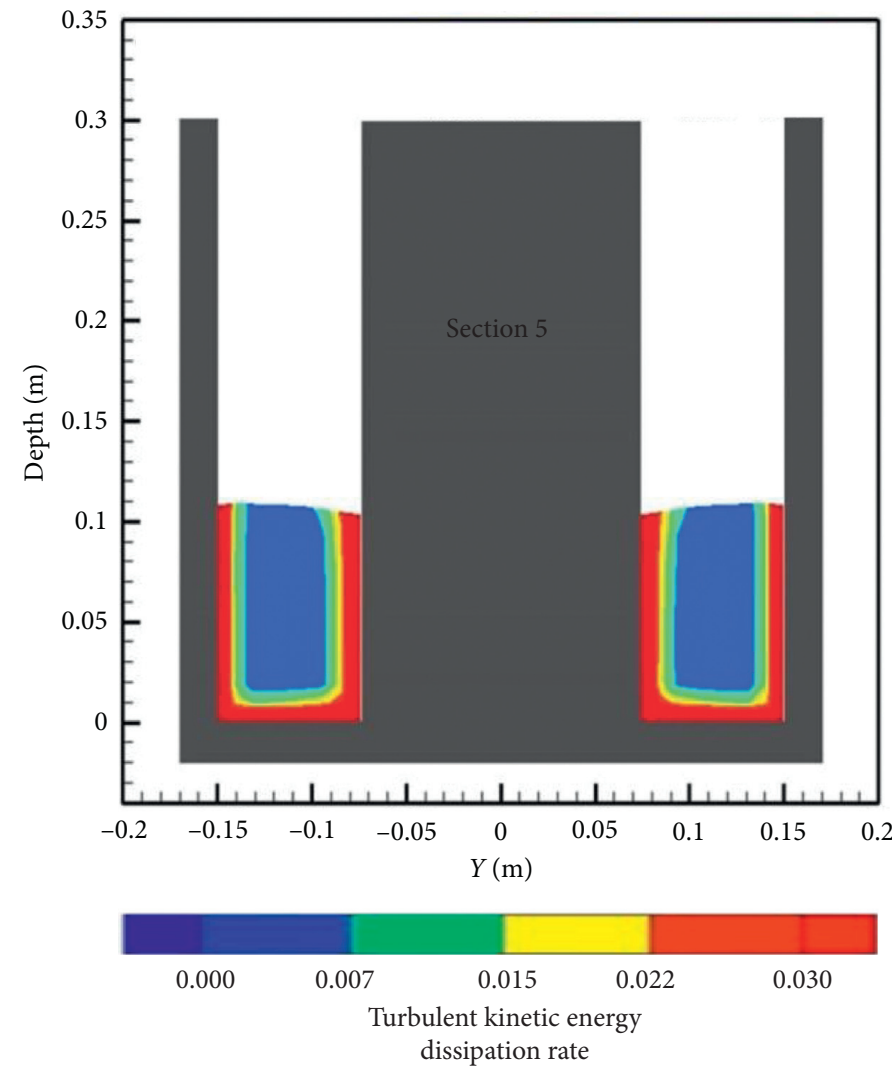

(c)

Figure 11: Continued. 


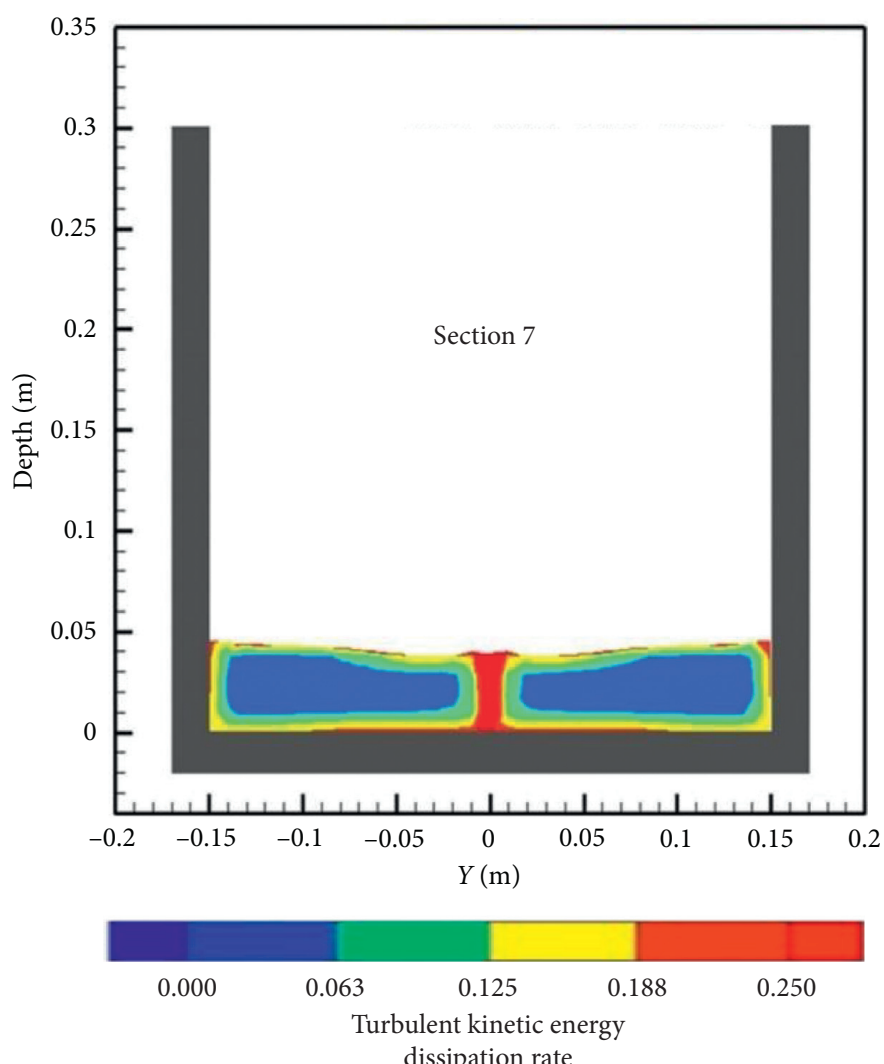

dissipation rate

(d)

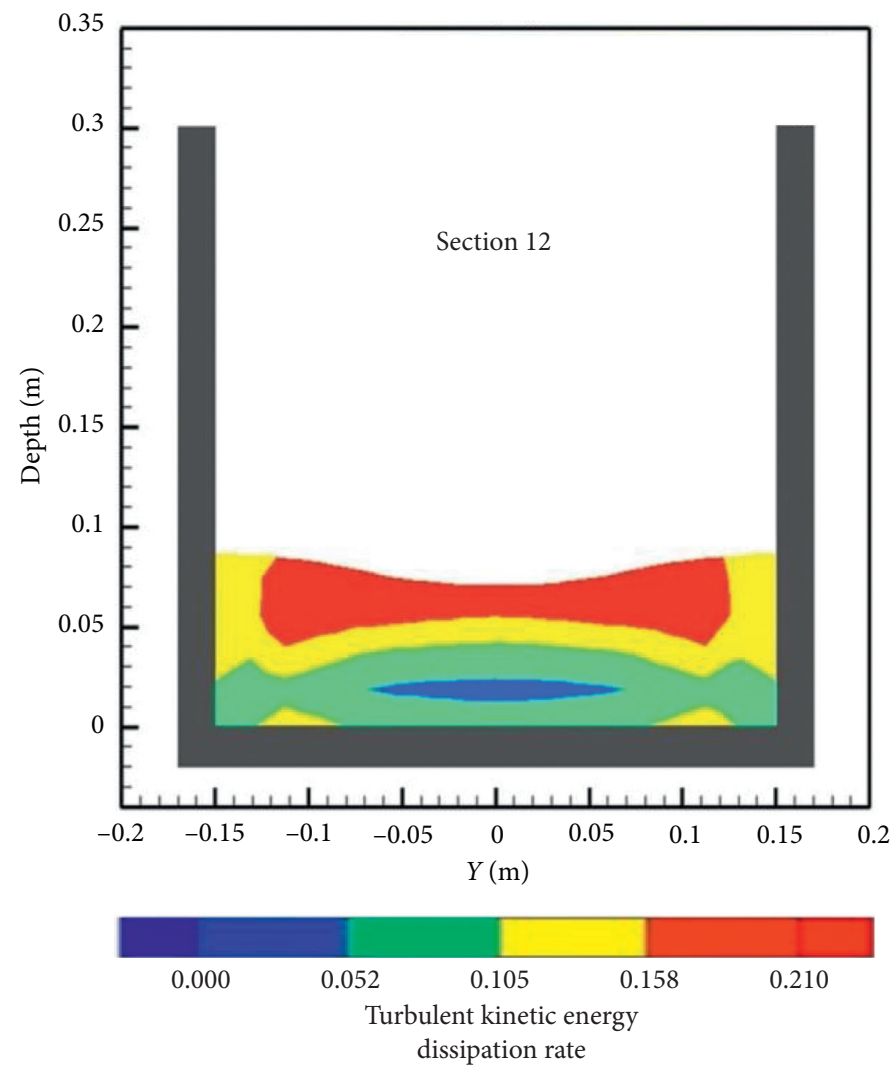

(e)

Figure 11: Continued. 


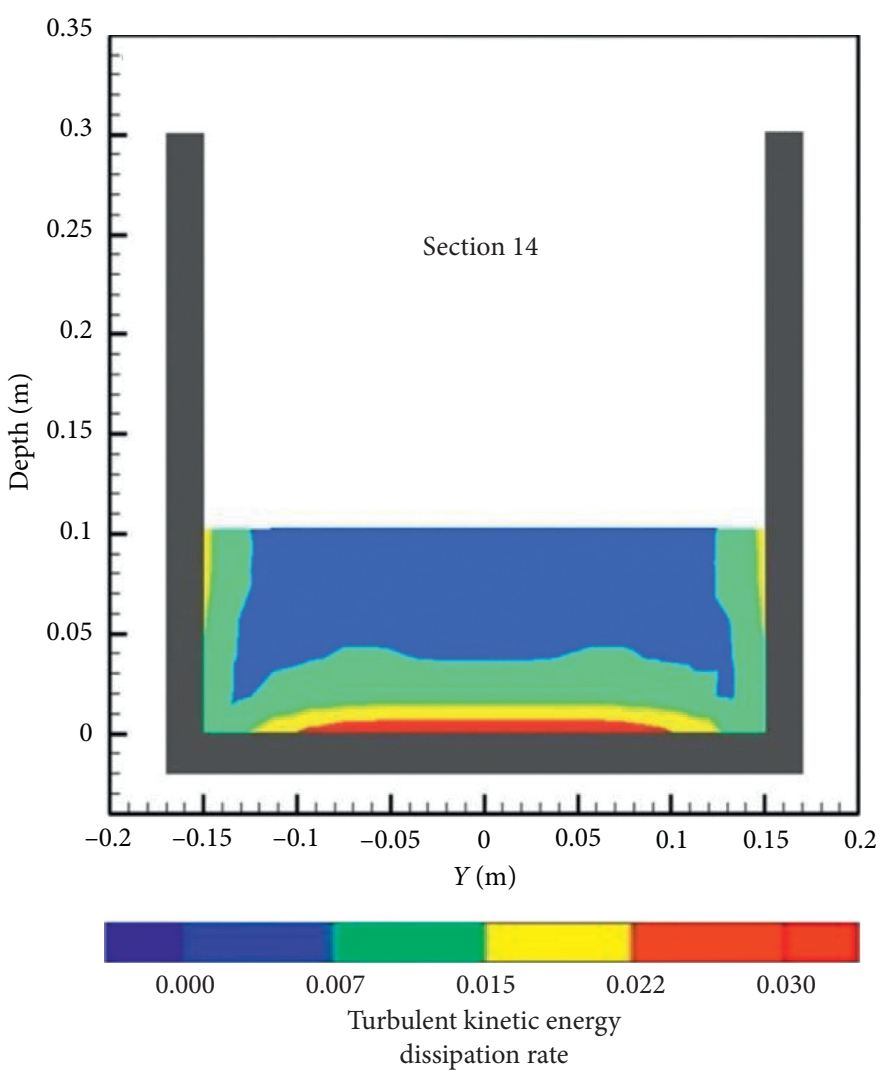

(f)

Figure 11: Development of cross-sectional turbulent kinetic energy dissipation rate (unit: $\mathrm{m}^{2} \cdot \mathrm{s}^{-3}$ ).

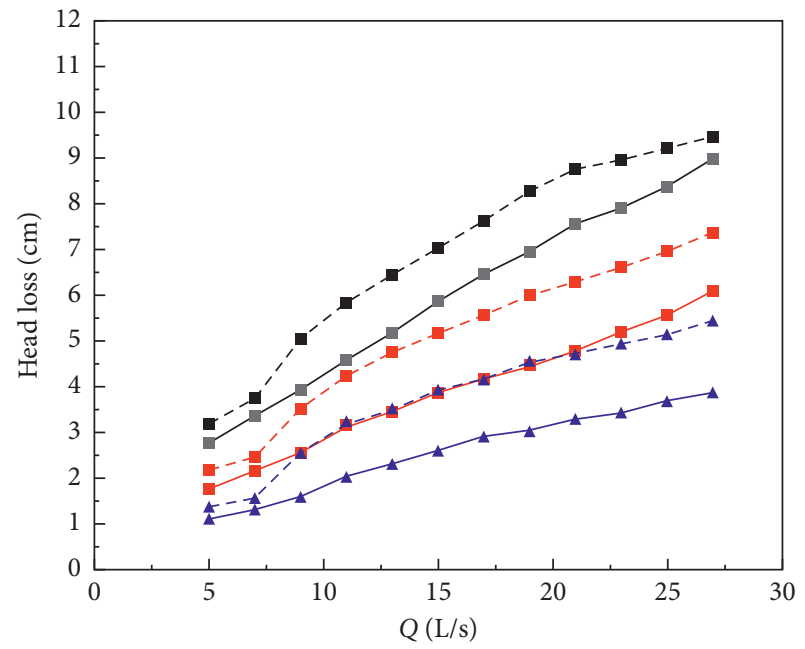

Protable pillar-shaped flume

$$
\begin{aligned}
& \multimap \varepsilon=0.4 \\
& \neg \varepsilon=0.5 \\
& \multimap \varepsilon=0.6
\end{aligned}
$$

Airfoil pillar-shaped flume

$$
\text { - - } \varepsilon=0.4
$$$$
-\square-\varepsilon=0.5
$$$$
-\star-\varepsilon=0.6
$$

FIgURE 12: Relationship between the head loss and flow rate at different contraction ratios.

upstream section of the flume is gentle, the flow in the front of the portable pillar-shaped flume is relatively slow, and the velocity distribution is relatively uniform. Furthermore, the

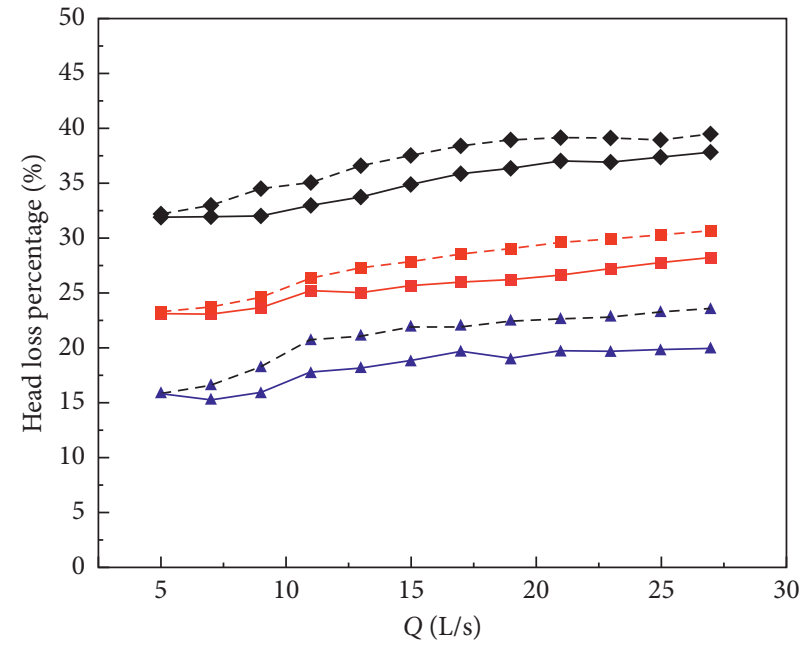

$$
\begin{array}{ll}
\text { Protable pillar-shaped flume } & \text { Airfoil pillar-shaped flume } \\
\leftarrow \varepsilon=0.4 & --\varepsilon=0.4 \\
\neg \varepsilon=0.5 & --\varepsilon=0.5 \\
\neg \varepsilon=0.6 & -\downarrow-\varepsilon=0.6
\end{array}
$$

FIGURE 13: Relationship between the percentage of head loss and flow rate at different contraction ratios.

time-averaged flow velocity of the water is larger in the middle of the section than on the side wall, and the maximum time-averaged flow velocity is achieved near the water 


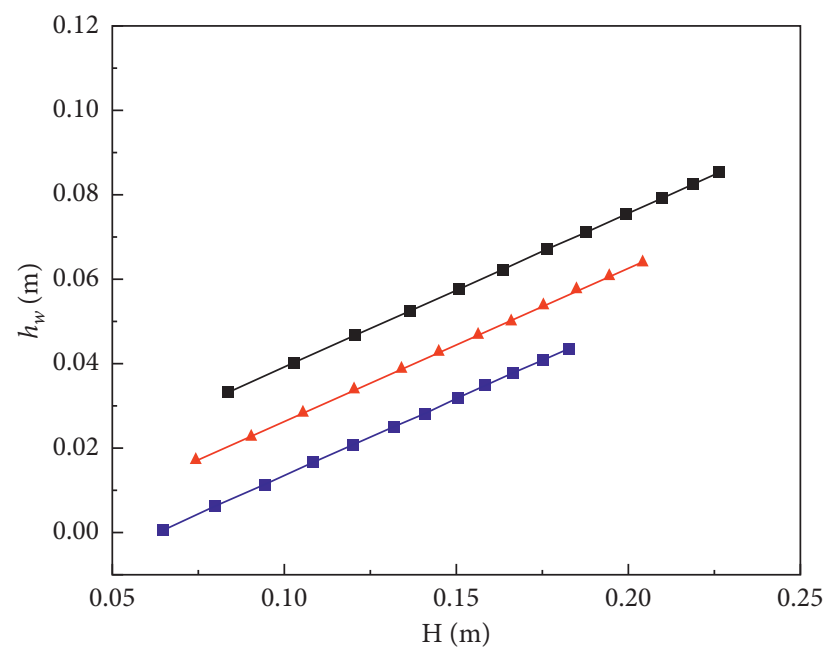

$\begin{aligned} \text { Equation } 31 & \text { Experimental results } \\ \varepsilon=0.4 & \text { - } \varepsilon=0.4 \\ -\varepsilon=0.5 & \Delta \varepsilon=0.5 \\ -\varepsilon=0.6 & -\varepsilon=0.6\end{aligned}$

FIGURE 14: Relationship between the head loss $\left(h_{w}\right)$ and the upstream water depth $(\mathrm{H})$ at different contraction ratios.

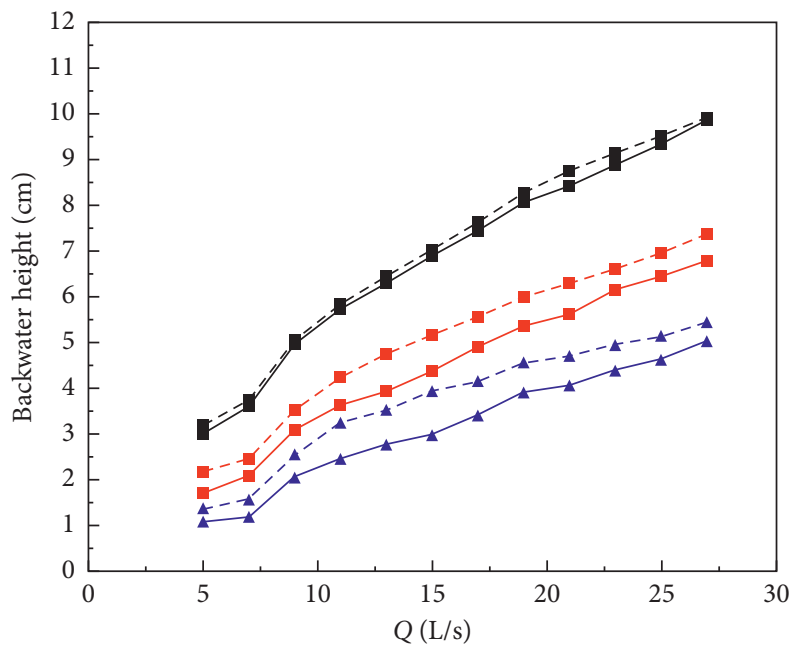

$$
\begin{aligned}
& \text { Protable pillar-shaped flume Airfoil pillar-shaped flume } \\
& \begin{aligned}
\rightarrow \varepsilon & =0.4 & -\square & -\varepsilon=0.4 \\
-\varepsilon & =0.5 & -\square & -\varepsilon=0.5 \\
\longleftarrow \varepsilon & =0.6 & - & -\varepsilon=0.6
\end{aligned}
\end{aligned}
$$

Figure 15: The variation of the backwater height of the portable pillar-shaped flume versus discharge rate.

surface. Figure 16(b) clearly illustrates the velocity distribution of the water flow in the first section (Section 2) of the flume, and the velocity of the intermediate water flow is close to zero. Affected by the central pillar, the water flow velocity gradually increases from the central pillar to both sides, reaching the maximum value between the central pillar and the side wall when entering the contraction section of the portable pillar-shaped flume. As shown in Figure 16(c), the flow velocity distribution gradually becomes uneven due to the gradual decrease of the overcurrent section, the gradual increase in the speed of water, and the deflection of the streamline due to the inertia effect. Figure 16(d) demonstrates that the water depth in the outlet section of the flume drops, and the flow velocity further rises. Also, the maximum flow velocity is achieved near the water surface. Figure 16(e) also depicts the flow velocity distribution in the downstream section of the flume. Under the influence of the portable pillar-shaped flume, the flow direction of the water flowing out of the flume is deflected, which causes the water flowing through the flume to diffuse, converge, and form a water jump. After the water jump, the flow velocity becomes uniform and the maximum velocity is obtained in the middle and lower parts of the flow, as displayed in Figure 16(f). 


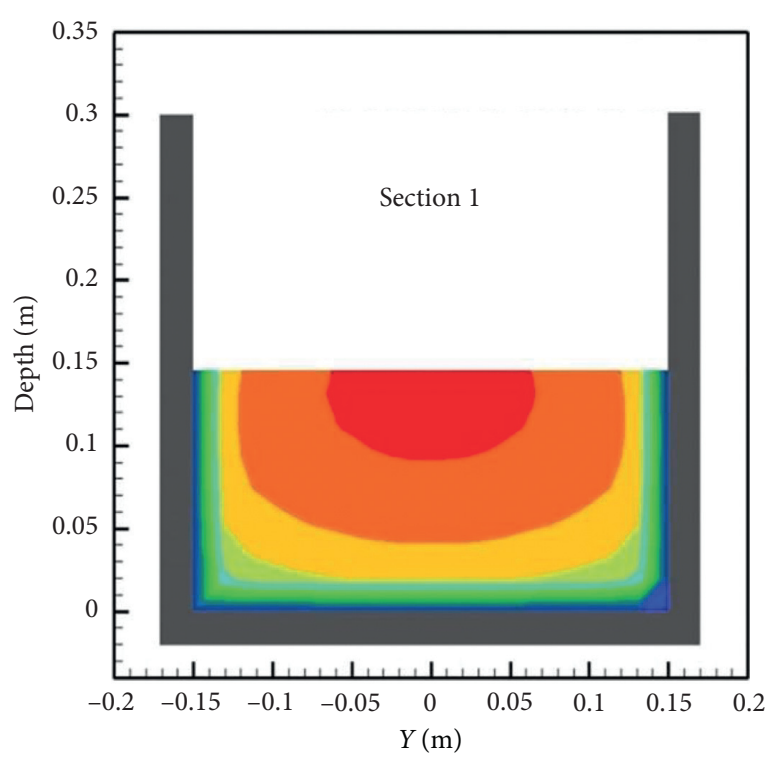

$\begin{array}{llllllllll}0.00 & 0.05 & 0.09 & 0.14 & 0.19 & 0.23 & 0.28 & 0.33 & 0.37 & 0.42\end{array}$ Velocity

(a)

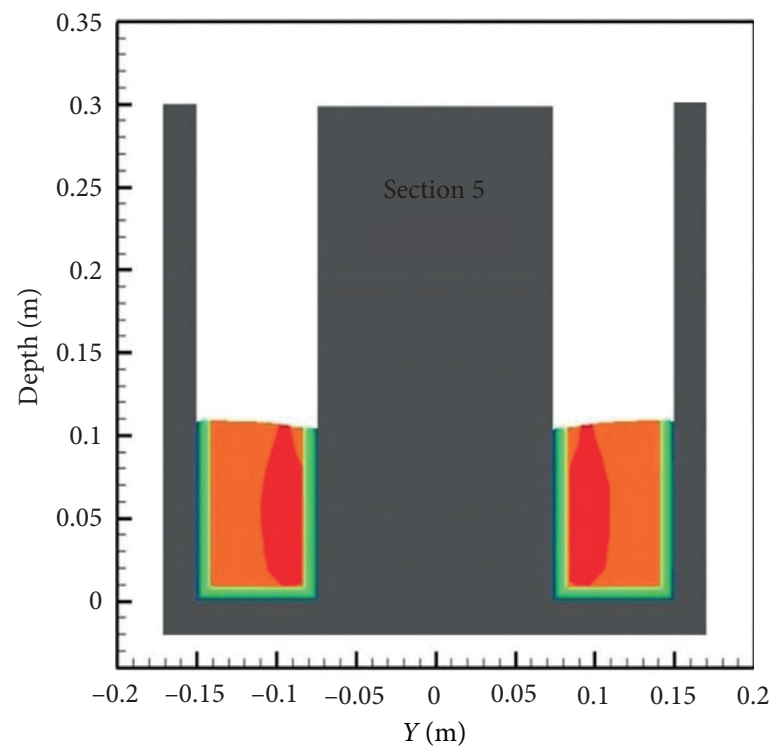

$\begin{array}{llllllllll}0.00 & 0.11 & 0.22 & 0.34 & 0.45 & 0.56 & 0.67 & 0.79 & 0.90 & 1.01\end{array}$ Velocity

(c)

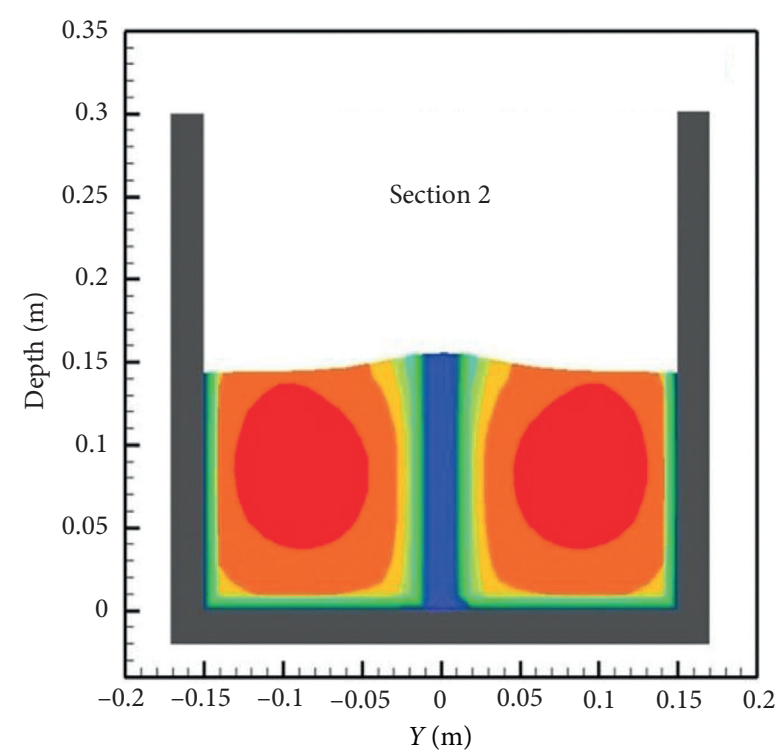

$\begin{array}{llllllllll}0.00 & 0.05 & 0.10 & 0.15 & 0.20 & 0.25 & 0.30 & 0.35 & 0.40 & 0.45\end{array}$ Velocity

(b)

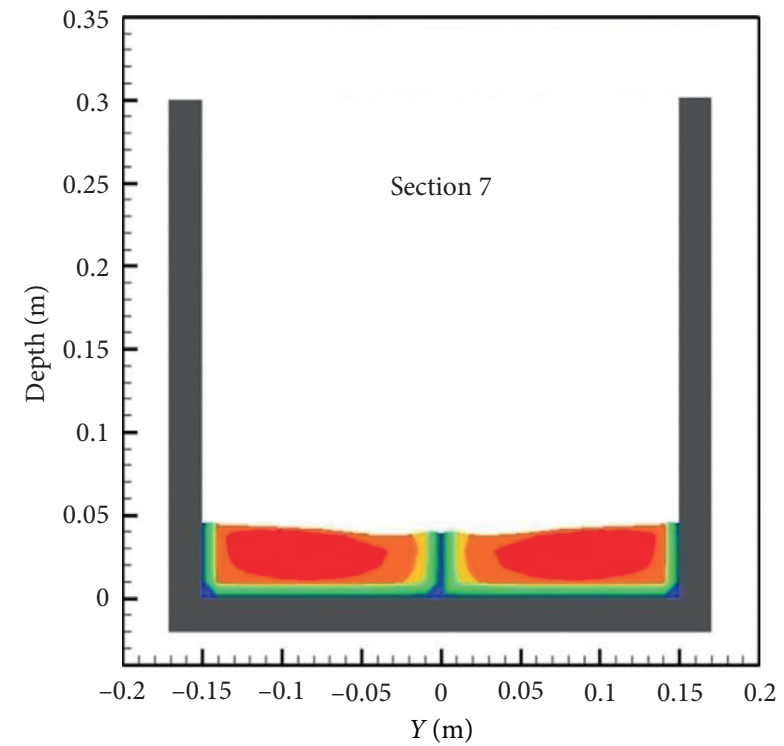

$\begin{array}{llllllllll}0.00 & 0.15 & 0.30 & 0.45 & 0.60 & 0.75 & 0.90 & 1.05 & 1.20 & 1.35\end{array}$ Velocity

(d)

Figure 16: Continued. 

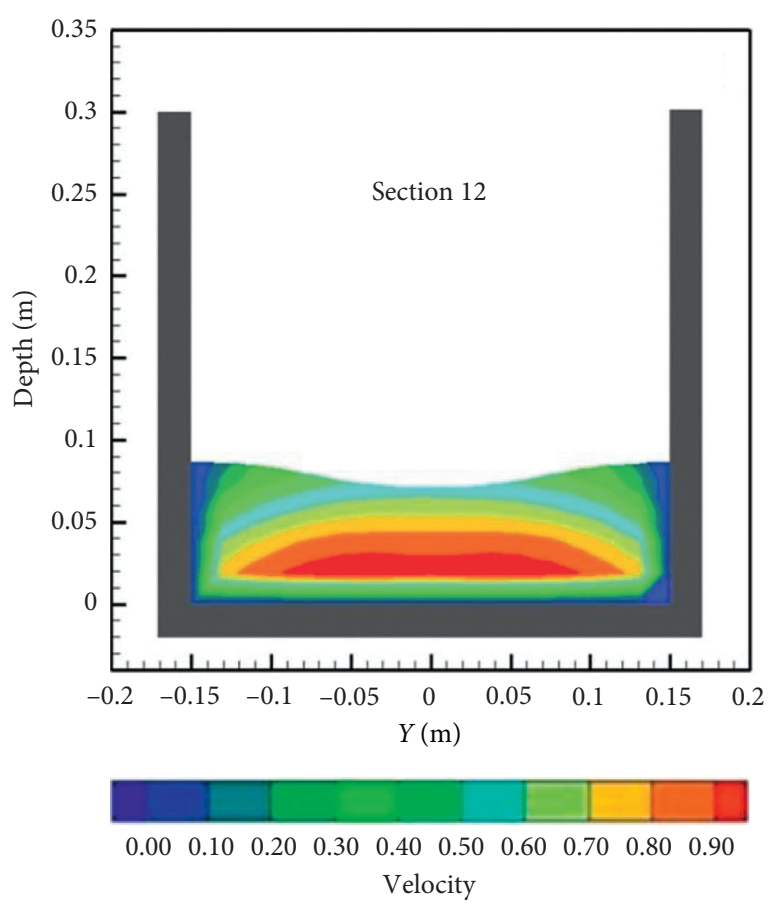

(e)
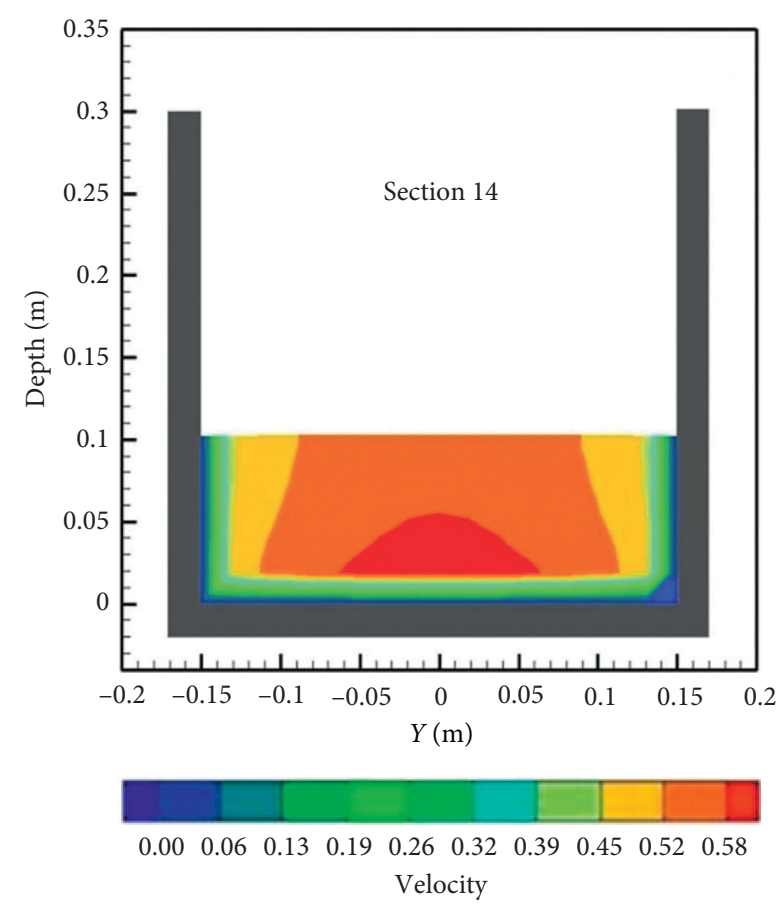

(f)

Figure 16: Development of the cross-sectional velocity distributions of the longitudinal flow of the water at a flow rate of $15 \mathrm{~L} / \mathrm{s}$ and a contraction ratio of 0.5 (unit: $\mathrm{m} \cdot \mathrm{s}^{-1}$ ).

\section{Conclusions}

For the purpose of reducing head loss and backwater height of discharge measurement, this study reports on a portable pillar-shaped flume. Based on Fluent 19.2 software, the standard $k-\varepsilon$ turbulence model is used to carry out a threedimensional numerical simulation of the portable pillarshaped flume, and the simulation data are verified using experimental results. The obtained results show that the simulation data are consistent with the experimental results; also, the maximum relative error in water depth is $8.65 \%$. The Froude number at the inlet of the portable pillar-shaped flume is less than 0.5 , which meets the requirements for discharge measurement. The relative error in the maximum flow measurement of the portable pillar-shaped flume is $4.74 \%$, and the relative error in the average flow measurement is $1.72 \%$. The portable pillar-shaped flume has a small backwater height, and its critical submergence degree is large; in fact, the critical submergence is between 0.73 and 0.96 , which suits the portable pillar-shaped flume to existing channels. Furthermore, with a certain degree of measurement accuracy, the head loss of the portable pillar-shaped flume is smaller than that of the airfoil pillar-shaped flume and present higher flow capacity. In addition, the portable pillar-shaped flume with a simple structure and a small size is convenient to carry and install. On the whole, it is concluded that the portable pillarshaped flume has the advantages of easy installation, simple structure, high accuracy, high critical submergence degree, small head loss, small backwater height, and suitability for application in constructed channels.

\section{Data Availability}

The data used to support the findings of this study are included within the article.

\section{Conflicts of Interest}

The authors declare that there are no conflicts of interest regarding the publication of this paper.

\section{Acknowledgments}

The authors gratefully acknowledge the support provided by the National Natural Science Foundation of China (no. 51909242).

\section{References}

[1] A. S. Ramamurthy and R. Tadayon, "Numerical simulation of flows in cut-throat flumes," Journal of Irrigation and Drainage Engineering, vol. 134, no. 6, pp. 857-860, 2008

[2] W. Dabrowski and U. Polak, "Improvements in flow rate measurements by flumes," Journal of Hydraulic Engineering, vol. 138, no. 8, pp. 757-763, 2012.

[3] C. I. Thornton, B. A. Smith, S. R. Abt, and M. D. Robeson, "Supercritical flow measurement using a small Parshall flume," Journal of Irrigation and Drainage Engineering, vol. 135, no. 5, pp. 683-692, 2009.

[4] W. Boiten, "Flow measurement structures," Flow Measurement and Instrumentation, vol. 13, no. 5-6, pp. 203-207, 2002. 
[5] Z. Samani, "Three simple flumes for flow measurement in open channels," Journal of Irrigation and Drainage Engineering, vol. 143, no. 6, 2017.

[6] A. R. Vatankhah and A. Mahdavi, "Simplified procedure for design of long-throated flumes and weirs," Flow Measurement and Instrumentation, pp. 79-84, 2012.

[7] V. Cone, The Venturi Flume, US Government Printing Office, Washington, DC, USA, 1917.

[8] R. L. J. C. Parshall, The Improved Venturi flume, SpringerVerlag, Berlin Heidelberg, Germany, 1928.

[9] G. V. Skogerboe, M. L. Hyatt, and J. D. England, Design and Calibration of Submerged Open Channel Flow Measurement Structures: Part 2-Parshall Flumes, Utah State University, Logan, Utah, 1967.

[10] G. V. Skogerboe, M. L. Hyatt, and K. O. Eggleston, Design and Calibration of Submerged Open Channel Flow Measurement Structures: Part 1-Submerged Flow, Utah State University, Logan, Utah, 1967.

[11] G. V. Skogerboe, M. L. Hyatt, and J. D. England, Measuring Water with Parshall Flumes, Utah State University, Logan, Utah, 1966.

[12] H. Zhu, G. Li, and J. Wang, "Flow-induced vibration of a circular cylinder with splitter plates placed upstream and downstream individually and simultaneously," Applied Ocean Research, vol. 97, Article ID 102084, 2020 pages.

[13] J. Wang, S. Zhou, Z. Zhang, and D. Yurchenko, "High-performance piezoelectric wind energy harvester with Y-shaped attachments," Energy Conversion and Management, vol. 181, pp. 645-652, 2019.

[14] J. Wang, L. Tang, L. Zhao, and Z. Zhang, "Efficiency investigation on energy harvesting from airflows in HVAC system based on galloping of isosceles triangle sectioned bluff bodies," Energy, vol. 172, pp. 1066-1078, 2019.

[15] G. Hu, J. Wang, Z. Su, G. Li, H. Peng, and C. S. Kwok, "Performance evaluation of twin piezoelectric wind energy harvesters under mutual interference," Applied Physics Letters, vol. 115, no. 7, 2019.

[16] J. Wang, L. Tang, L. Zhao, G. Hu, R. Song, and K. Xu, "Equivalent circuit representation of a vortex-induced vibration-based energy harvester using a semi-empirical lumped parameter approach," International Journal of Energy Research, vol. 44, no. 6, pp. 4516-4528, 2020.

[17] W. H. Hager, "Modified venturi channel," Journal of Irrigation and Drainage Engineering, vol. 111, no. 1, pp. 19-35, 1985.

[18] F. L. Kolavani, M. Bijankhan, and C. Di Stefano, "Experimental study of central baffle flume," Journal of Irrigation and Drainage Engineering, vol. 145, no. 3, Article ID 04019002, 14 pages, 2019.

[19] M. Bijankhan and V. Ferro, "Experimental study on triangular central baffle flume," Flow Measurement and Instrumentation, vol. 70, Article ID 101641, 7 pages, 2019.

[20] B. Sun, H. Lv, and C. Song, "Multi-objective optimization of airfoil-shaped hydraulic structure based on hicks-henne shaped function and MIGA," Journal of Sichuan University, vol. 45, no. 04, pp. 13-20, 2013, (in Chinese).

[21] H. Hu, J. Huang, Z. Qian, W. Huai, and G. Yu, "Hydraulic analysis of parabolic flume for flow measurement," Flow Measurement and Instrumentation, vol. 37, pp. 54-64, 2014.

[22] H. Zhu, J. Yao, Y. Ma, H. Zhao, and Y. Tang, "Simultaneous CFD evaluation of VIV suppression using smaller control cylinders," Journal of Fluids and Structures, vol. 57, pp. 66-80, 2015.

[23] H. Zhu and J. Yao, "Numerical evaluation of passive control of VIV by small control rods," Applied Ocean Research, vol. 51, pp. 93-116, 2015.
[24] H. Zhu, W. Liu, and T. Zhou, "Direct numerical simulation of the wake adjustment and hydrodynamic characteristics of a circular cylinder symmetrically attached with fin-shaped strips," Ocean Engineering, vol. 195, Article ID 106756, 2020 pages.

[25] K. Yang, J. Wang, and D. Yurchenko, “A double-beam piezomagneto-elastic wind energy harvester for improving the galloping-based energy harvesting," Applied Physics Letters, vol. 115, no. 19, 2019.

[26] Y. Xiao, W. Wang, X. Hu, and Y. Zhou, "Experimental and numerical research on portable short-throat flume in the field," Flow Measurement and Instrumentation, vol. 47, pp. 54-61, 2016.

[27] X. Li, L. Jin, and B. A. Engel, "Influence of the structure of cylindrical mobile flumes on hydraulic performance characteristics in U-shaped channels," Flow Measurement and Instrumentation, vol. 72, 2020.

[28] N. R. B. Olsen and H. M. Kjellesvig, "Three-dimensional numerical flow modelling for estimation of spillway capacity," Journal of Hydraulic Research, vol. 36, no. 5, pp. 775-784, 1998.

[29] G. E. Ferrari, M. Politano, and L. Weber, "Numerical simulation of free surface flows on a fish bypass," Computers \& Fluids, vol. 38, no. 5, pp. 997-1002, 2009.

[30] F. Xiao and A. Ikebata, "An efficient method for capturing free boundaries in multi-fluid simulations," International Journal for Numerical Methods in Fluids, vol. 42, no. 2, pp. 187-210, 2003.

[31] C. W. Hirt and B. D. Nichols, "Volume of fluid (VOF) method for the dynamics of free boundaries," Journal of Computational Physics, vol. 39, no. 1, pp. 201-225, 1981.

[32] L. Jiang, M. Diao, and H. Sun, "Numerical modeling of flow over a rectangular broad-crested weir with a sloped upstream face," Water, vol. 10, no. 11, 2018.

[33] A. N. Ziaei, N. S. R. Nikou, A. Beyhaghi, F. Attarzadeh, and S. R. Khodashenas, "Flow simulation over a triangular labyrinth side weir in a rectangular channel," Progress in Computational Fluid Dynamics, An International Journal, vol. 19, no. 1, pp. 22-34, 2019.

[34] H. Saadatnejadgharahassanlou, R. I. Zeynali, and A. Gharehbaghi, "Three dimensional flow simulation over a sharp-crested V-Notch weir," Flow Measurement and Instrumentation, vol. 71, 2020.

[35] F. G. Carollo, C. Di Stefano, and V. Ferro, "New stage-discharge equation for the SMBF flume," Journal of Irrigation and Drainage Engineering, vol. 142, no. 5, 2016.

[36] H. Liu, R. Zhao, and J. Huang, "Experimental Research on Airfoil Pillar-shaped Measuring-flume," China Rural Water and Hydropower, vol. 06, pp. 170-172, 2014, (in Chinese). 